Portland State University

PDXScholar

Spring 9-4-2019

\title{
"Smart" Technology: Do You Buy It? Adoption of Digital Innovations
}

Laura Koyer Glass

Portland State University

Follow this and additional works at: https://pdxscholar.library.pdx.edu/open_access_etds

Part of the Communication Commons

Let us know how access to this document benefits you.

Recommended Citation

Glass, Laura Koyer, "'Smart" Technology: Do You Buy It? Adoption of Digital Innovations" (2019).

Dissertations and Theses. Paper 5264.

https://doi.org/10.15760/etd.7137

This Thesis is brought to you for free and open access. It has been accepted for inclusion in Dissertations and Theses by an authorized administrator of PDXScholar. Please contact us if we can make this document more accessible: pdxscholar@pdx.edu. 
"Smart" Technology: Do You Buy It?

Adoption of Digital Innovations

by

Laura Koyer Glass

A thesis submitted in partial fulfillment of the requirements for the degree of

Master of Science

in

Communication

Thesis Committee:

Lauren Frank, Chair

Brianne Suldovsky

Brian Manata

Portland State University

2019 


\begin{abstract}
With the increase in "smart" devices that connect to the internet, it is important to study how individuals perceive characteristics of innovations and how those perceptions relate to adoption behavior. This paper explores how attributes delineated by the diffusion of innovations (DOI) model (relative advantage, compatibility, visibility, trialability) and technology acceptance models (TAMs; perceived usefulness, ease of use) correlate with one's interest in using an internet-connected device. Eligible survey responses were collected from 116 participants which evaluated individual perceptions of new technology. Subsequently, quantitative analysis explored the relationship between individuals' technology perceptions and purchasing intentions. The current research extends pre-existing models by finding that social influence and device customizability play key roles in one's intent to purchase. Research incorporating these factors into the diffusion of innovations model and technology acceptance models will not only improve the design process for future devices but also will influence the objectives of current technology marketing efforts.
\end{abstract}

Keywords: digital technology, adoption, marketing, diffusion of innovations, technology acceptance model 


\section{Dedication}

I would like to dedicate this thesis to Charlie Slominski, who has supported me in so many ways throughout this academic journey.

Additionally, I would like to dedicate this to my parents, Steven and Carol Glass.

Without their encouragement and support, so much of what I have done would not have been possible. 


\section{Acknowledgements}

Dr. Lauren Frank, you have pushed me to always work harder and try to achieve my best. Thank you for your advice, suggestions, and encouragement over the past two years. Your enthusiasm for Communication has made my graduate school experience overwhelmingly positive.

Dr. Brianne Suldovsky and Dr. Brian Manata, your input and suggestions have challenged me, yet provided the guidance I have needed, to write my thesis. Thank you.

Zoe Larson and Dan Vandehey, you are some of the best cohort members I could have ever hoped for. Your competitive spirits and collaborative attitudes have helped me reach new heights in my academic pursuits. Your friendships have helped me grow both personally and professionally, and I truly hope that we have opportunities to work together again in our future careers. 


\section{Table of Contents}

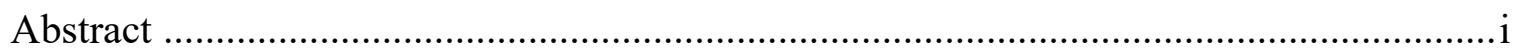

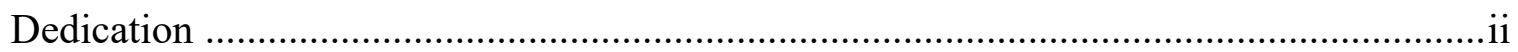

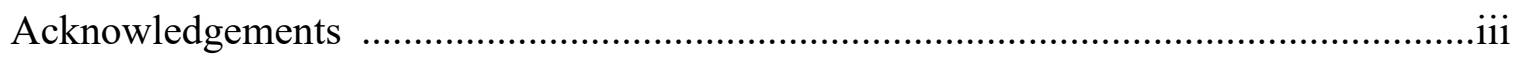

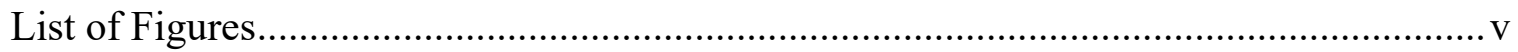

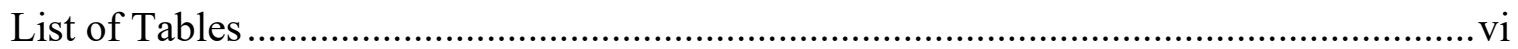

\section{Chapter 1}

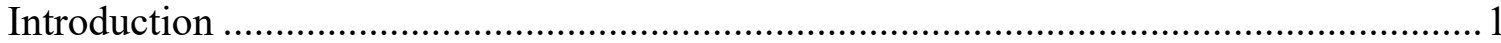

Chapter 2

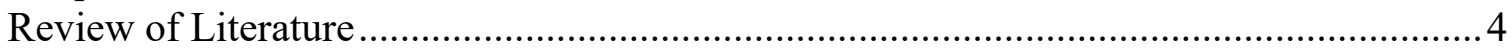

Chapter 3

Methods

Chapter 4

Results

Chapter 5

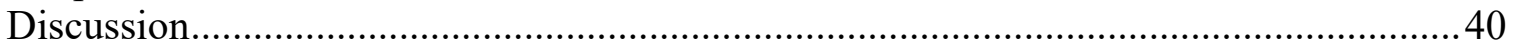

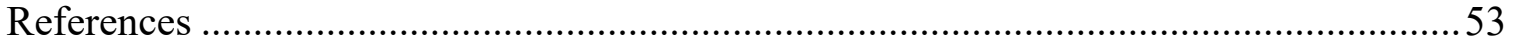

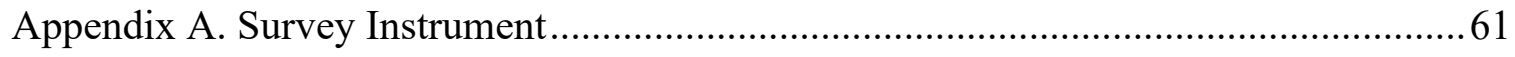

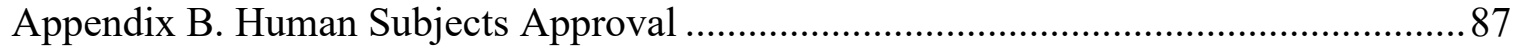


List of Figures

Figure 1: Hypothesized relationships between constructs....................................... 18

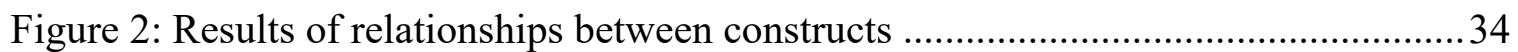




\section{List of Tables}

Table 1: Means and standard deviations of technology attributes................................ 31

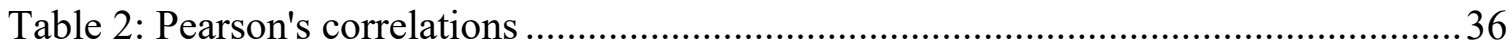

Table 3: Multiple linear regression predicting intention to purchase a new technology...37 


\section{Chapter One: Introduction}

A fridge has been discovered sending out spam after a web attack managed to compromise smart gadgets.... The fridge was one of more than 100,000 devices used to take part in the spam campaign.... The malware managed to get itself installed on... smart devices such as kitchen appliances..., home media systems..., and web-connected televisions.... (Clarke, 2014)

BBC released this news story in 2014 about "smart" home appliances and how decreased security protections have allowed individuals to hack into the systems of connected devices and create havoc. Gartner (Hung, 2017) predicted that there will be 20 billion "connected" Internet of Things (IoT) devices by 2020. Internet of Things (IoT) devices are inherently designed to connect to the internet and represent just one type of digital technology. Forbes has predicted a 17\% growth in software development jobs from 2014 to 2024 , "'much faster' than the average growth rate among other professions," which means that these devices will both be created and hacked more often in the upcoming years (Mazaika, 2017, para. 7).

Recent consumer developments in Internet of Things devices include products ranging from wearables, to cars, to home appliances. In 2017, a "smart" refrigerator was named Best Smart Appliance (PC Mag Staff, 2017; CES, 2018). The "smart" refrigerator has the capability to take photographs of your food to view on your smartphone and can connect to your "smart" devices at home to make grocery lists or play music (PC Mag Staff, 2017).

Our personal information is becoming increasingly available because of our interaction with these devices. Business leaders sometimes view digital technology 
products, such as these, as solutions for "the myriad [of information technology] and business problems that their organizations [face]" (Hung, 2017, p. 6-7). Some organizations message business teams through Slack, colleagues ride to work using Uber, and employees order lunch through Foodler and then pay with Apple Pay. Outside of work, individuals "wake up to an alarm set on Amazon Alexa" and watch Netflix "on demand before heading to bed" (Mazaika, 2017, para. 2). Despite the ubiquity of digital devices and the dependence that our society has on technology, some individuals still remain skeptical about the use and acceptance of new, "smart" digital technologies that connect to the internet. It is worth considering the specifics regarding how and why individuals might have reservations about new technologies, so that future innovations can cater to the concerns and advantages that consumers see in technology.

Chapter 2 discusses the theoretical and empirical evidence surrounding public opinion toward technology, the diffusion of innovations model, technology acceptance models, and social network theory. In researching these topics, I have developed two research questions and a set of hypotheses that further examine the process of technology adoption. Additionally, in Chapter 3, I describe the survey method with which I conducted my research. I present information on the participants in this study and describe my process of scale development. Chapter 4 explains the results of my data collection. While knowledge, social influence, and the technology attributes of compatibility, visibility, trialability, relative advantage/ perceived usefulness, ease of use, and customizability appear to be significantly correlated with one's intent to purchase, a linear regression model shows that social influence, relative advantage/ perceived usefulness, and customizability are significant predictors of one's decision. In Chapter 5, I 
discuss how these results align with and elaborate on past research, in addition to mentioning limitations of this study regarding the participant population and survey design. I also suggest that future research continues to evaluate the adoption of "smart" technology and that future studies incorporate individuals' perceptions of privacy concerns for this type of product. 


\section{Chapter Two: Review of Literature}

In this chapter, I define the key terms that are relevant to my research and discuss theoretical and empirical evidence surrounding technology adoption. I include information about public opinion toward technology and then describe theories such as the diffusion of innovations model, variations on technology acceptance models, and how social network theory might influence decisions surrounding technology adoption. With this research, I intend to expand upon existing models that seek to explain the reasons behind adoption of technology innovations.

\section{Public Opinion towards New Technology}

The Pew Research Center published a report in October 2017 that evaluated how Americans view the role of digital technology in the future (Smith \& Anderson, 2017). In general, respondents expressed greater concern than enthusiasm regarding a future with new technologies such as driverless vehicles (Smith \& Anderson, 2017). Individuals seem hesitant to use various automation technologies themselves (i.e. "56\% of individuals would not want to "ride in a driverless vehicle," Smith \& Anderson, 2017, p. 4). Regarding new driving technologies, $94 \%$ of respondents had heard about the development of driverless vehicles, yet only $22 \%$ of those individuals had heard mostly positive things about their development (Smith \& Anderson, 2017).

Additionally, past research shows that one's level of knowledge about technology is related to one's interest in technology. Widavsky and Dake (1990) found that the more knowledge an individual has "(based on information given to participants) is inversely related to fear of a technology" (Widavsky \& Dake, 1990, p. 54). The authors add that it is not necessarily a higher level of "knowledge per se, but confidence... and credibility of 
[the] information that someone holds" (Widavsky \& Dave, 1990, p. 54). To explore how one's level of technology knowledge might relate to one's interest in purchasing a specific technology, I propose the following two research questions.

RQ1: How does one's level of knowledge about technology, in general, correlate with one's interest in purchasing a specific new technology?

RQ2: How does one's level of knowledge about a specific technology correlate with one's interest in purchasing a specific new technology?

\section{Diffusion of innovations (DOI) model}

The diffusion of innovations model explains how a new idea or technology is "communicated through certain channels over time among... a social system" (Rogers, 2003, p. 5). Diffusion is the process by which all things (ideas, products, people, etc.) spread over time and, therefore, this model is inherent to all processes involving the spread of digital technology (Rice, 2009; Rogers, 1962). Rogers defines an innovation as "an idea, practice, or object that is perceived as new by an individual or another unit of adoption" (Rogers, 2003, p. 36). In most circumstances, an experience with uncertainty spurs information gathering which leads to learning about and adopting an innovation. Some individuals know about and understand technologies yet choose not to adopt them for a variety of other reasons (Rogers, 2003).

"New technologies" are often used synonymously with "innovations" within the DOI model (Rogers, 2003, p. 13). Technology innovations often have both a hardware and a software component, but also can constitute just one or the other. Hardware relates to the physical object, while software relates to a thought or process by which the physical object runs. While it is possible to have only a software component, the 
diffusion of software is more difficult to observe. Also, digital technology is not the only type of technology with hardware and software. For example, public health campaigns that encourage a new behavior, such as the use of condoms to prevent the spread of HIV, could be considered a software innovation This would not be as observable as a hardware innovation unless it was coupled with a visible indication of software use, such as the wearing of a pin to symbolize that one practices safe intercourse (Rogers, 2003).

The coupling of two innovations (i.e., a software innovation and a hardware innovation), referred to as a technology cluster, often results in more rapid diffusion since the hardware component is often more observable than the software component (Rogers, 2003). In some circumstances, two software or two hardware technologies can also constitute a technology cluster. Greater compatibility of the technology cluster, which occurs when a technology better fits the needs of the consumer, contributes to a higher rate of innovation adoption (Rogers, 2003). Rogers (2003) noted how invention of the mobile phone, for example, was a technology cluster (comprised of both a physical device and a telecommunication system) that skyrocketed after its debut to American consumers in 1983. Despite the novelty of mobile phone devices, the software within the phone contributed to the public's continued interest and excitement, which further encouraged mobile phone adoption (Rogers, 2003).

Innovation attributes. Often, over half of the variance for innovation adoption is due to five distinct attributes of how an individual perceives an innovation: relative advantage, compatibility, complexity, observability, and trialability (Rogers, 2003). It is important to emphasize that, despite the inherent characteristics of an innovation, it is an 
individual's perception of these attributes that affects whether or not that individual chooses to adopt that innovation.

Generally, relative advantage refers to the positive attributes that a novel innovation has compared to previous innovations. It is one of the more common attributes measured, as it often acts as a broad category consisting of more specific attributes such as how an innovation contributes to economic or status advantage (Rogers, 2003; Tornatzky \& Klein, 1992). Status advantage is the perception that there are social benefits resulting from one's adoption of an innovation. The fashion industry, for example, thrives on providing innovations in clothing that increase one's perception of him or herself in a social system. Without the assumption that a clothing item will contribute to an individual's social success, it is unlikely that clothing companies would be incentivized to develop new lines of clothing or that customers would continue to buy new clothes.

Compatibility refers to how well an innovation fits with an individual's sociocultural values and lifestyle (Rogers, 2003). As previously mentioned, the greater compatibility that an innovation or technology cluster has with one's lifestyle, the more quickly it will be adopted. Boiling water to prevent infectious disease, for example, is a software innovation in Peru that quickly proved to not be compatible with the Peruvian lifestyle. This innovation was contrary to sociocultural values since the heating of water conflicted with superstitions behind drinking water that had been boiled. While not physically difficult, the boiling of water was shunned by $95 \%$ of individuals in a two-year campaign where sociocultural superstitions were not addressed (Rogers, 2003). If the 
compatibility of this practice with this Peruvian lifestyle had been elucidated prior to the campaign, perhaps additional measures could have facilitated campaign success.

Other innovations, on the other hand, are difficult to undertake, which might further prevent diffusion. Thus, the complexity of an innovation is another factor that affects diffusion rates. If a product is difficult to understand and use, it will be adopted more slowly than a product that is intuitive and perceived as helpful (Rogers, 2003). For example, personal computers, owned by more than $70 \%$ of Americans in 2015 , were originally adopted by individuals who enjoyed "technological gadgets..., had extensive experience with mainframe and/ or minicomputers" and who did not view the new technology as complex (Anderson, 2015; Roger, 2003, p. 243). Technology acceptance models, similarly, focus on understanding an individual's interaction with an innovation's complexity, which is identified as understanding an innovation's ease of use (Davis, 1989).

Observability measures how well an innovation's adoption and implementation are "visible to others" (Rogers, 2003, p. 244). Software technologies, for instance, are not always observable. As explained above with the example of mobile devices, the use of network technology is observed by the hardware that accompanies it, such as the mobile phone itself, rather than through discussion or observance of the network technology. Greater observability leads to greater levels of adoption since individuals inherently make decisions about innovations that they encounter and whether or not they want to incorporate them into their own lives (Rogers, 2003). Since software is not inherently tangible, software components are often promoted by being offered for specific hardware; 
the purchase of a given hardware will, subsequently, encourage adoption of and trace the adoptability of, new software (Rogers, 2003).

Additionally, trialability explains the extent that an innovation can be "experimented with on a limited basis" (Rogers, 2003, p. 258). This can reduce uncertainty about an innovation and allow potential users to better understand subjective attributes, such as complexity, that might influence their decision to adopt a given innovation. During trials, re-invention of an innovation provides for an innovation to be "[customized]...more closely to [an] individual's conditions" (Rogers, 2003, p. 258). Reinvention is the modification to either the functionality or aesthetics of an innovation. When the re-invention is congruent and beneficial to an adopter's situation, it will often lead not only to a greater rate of adoption, but also to a greater likelihood of innovation sustainability (Rogers, 2003). After the original invention of the mobile phone, users became dissatisfied with the phone's indistinguishability from other mobile phones (Rogers, 2003). Options of customizability, such as color choice and decorative design elements, were soon introduced and encouraged not only individuality, but also subsequent innovation adoption by a wider range of consumers outside of the business sector (Rogers, 2003).

Adoption groups. Technologies are adopted at different stages by groups of people that hold different perceptions of new technologies and who have been categorized into five ideal groups within this model: innovators, early adopters, early majority, late majority, and laggards (Rogers, 2003). These groups are ideal because not all individuals realistically fall directly into one category. Depending on the past 
experiences of an individual and the specific innovation being considered, many people "fit" into more than one group.

The specific innovation and its relevance to potential adopters, socioeconomic factors, communication behavior, and personality generalizations define each category and aid in predicting whether and when one will adopt a new idea or technology (Rogers, 2003). In the category of mobile communication devices, for instance, Jiang's research identifies the behavioral aspects of younger generations that contribute to their adoption of innovations like the iPhone. When the iPhone announced its fourth generation phone, younger generations were initially drawn to the iPhone's ability to "connect individuals to wider social collectives," "[facilitate] the sharing of experiences [and] feelings," have a "unique user-interface," and act as "a 'part-time substitute"' to other electronic devices such as cameras and computers (Jiang, 2010, p. 36, 37). As mobile phone models continued to advance, however, the perceived attributes of these products that have become more appealing to demographics have changed. Older demographics, for example, are often more interested in mobile communication devices if the device offers perceived health facilitators, such as applications that send medical information to a doctor or accessibility features, like the option to buy a larger screen with bigger text (St. John, 2013). Depending on the kind of innovation, be it a digital communication device or behavioral change, different attributes could be more relevant for various adopter groups.

Adoption rate. "The rate of adoption is the relative speed with which an innovation is adopted by members of a social system" (Rogers, 2003, p. 37). Four components of diffusion (the type of innovation-decision, the channel(s) in which it is 
communicated, the extent of communication over time, and the social system) affect an innovation's rate of adoption. The innovation-decision process describes how an innovation is introduced and ultimately adopted by members in society. This is the process that dictates whether or not a novel technology will be mandatory or optional within a social system. Mandatory innovations might include the use of a computer software to standardize business practices within a company, whereas an optional innovation might be one's use of computer software on a personal computer. The rate of an innovation's adoption can sometimes be increased if fewer individuals, such as one individual instead of a company board, are involved in this decision process (Rogers, 2003). The consumer-focused digital technologies in the present study are considered voluntary innovation-adoption decisions. This might affect one's perceptions of technology attributes since the technology is not mandatory.

\section{Social Network Theory}

After the diffusion of innovations model encouraged thinking about how innovations spread, Burt (1999) expanded diffusion research by suggesting that opinion leaders propagate the flow of ideas as a result of their being socially connected and gaining personal, social benefits as a result. Accurately described by Burt, "opinion leaders are people whose conversations make innovations contagious for the people with whom they speak" (Burt, 1999, p. 11). The social benefits gained result from both informal and formal relationships between people. In some cases, the gains can be as intangible as an ego boost; in other cases, the sharing of knowledge can increase one's worth and lead to job referrals, resulting in positive outcomes for both an employer and future employee (Burt, 1999). Some individuals might feel that their application of a 
friend's knowledge shows their loyalty and respect to that friend. Social network theory seeks to understand "social relationships and how they help explain...[the] behavior" that propagates diffusion (Valente, 2008, p. 1). For example, an individual's "likelihood of adoption increases as the proportion of users in his or her personal network [increases]" (Valente, 1995, p. 101).

Interpersonal relationships are a key component of social network theory and the diffusion of innovations model (Liu, Sidhu, Beacom, \& Valente, 2017). Specifically, the interpersonal relationships between earlier adopters (innovators, early majority, early adopters) and others are sometimes what influence individuals to consider adoption (Rogers, 2003). Social network theory evaluates these relationships between individuals. Longitudinal studies have shown that individuals have stronger influence on others' adoption choices when part of more cohesive social subgroups (Liu, Sidhu, Beacom, \& Valente, 2017).

Additionally, past research has shown how social norms, both subjective and descriptive, affect how individuals act in various social situations (Chung \& Rimal, 2016; Cialdini, Reno, \& Kallgren, 1990; Manata, 2019; Park \& Smith, 2007; Rimal \& Lapinski, 2015). While descriptive norms delineate "what is typical or normal" and are defined by "what most people do" (Cialdini, Reno, \& Kallgren, 1990, p. 1015), subjective norms are defined by one's perceptions of what "important others" think one should do (Chung \& Rimal, 2016; Park \& Smith, 2007, p. 195). While it has been shown that descriptive norms are more influential when an individual's actions (i.e., one's possession of a new device) are more visible to others, subjective norms occur when "observation or judgement from others" might occur as a result of one's actions (Chung \& Rimal, 2016, p. 
16). A variety of norms can be salient in one's decisions when actions have social consequences (Chung \& Rimal, 2016; Rimal \& Lapinski, 2015). Due to the likelihood of social influence affecting one's decisions when adoption of a technology is visible to others, I propose $\mathrm{H} 1$.

H1: Social influence is positively correlated with one's interest in purchasing a specific new technology.

\section{Technology acceptance models}

The technology acceptance model (TAM) and the diffusion of innovations (DOI) model are often applied separately as theoretical background for empirical studies because "of the different time-scales involved and the types of data collected in [each of their] use" (Ward, 2013, p. 225). While the diffusion of innovations model focuses on longer time-scales and the diffusion process across the whole social system for an innovation, acceptance models focus on technology adoption by an individual. I have chosen to use both models as theoretical approaches to understanding technology adoption since individual adoption is integral to diffusion within a social system when the innovation-decision is made by an individual.

The technology acceptance model (TAM) is the basis for many (subsequent) models of technology acceptance that focus on identifying perceived innovation characteristics that predict technology adoption for an individual. Often these models evaluate the adoption of information technology (Dadayan \& Ferro, 2005). Tornatzky and Klein (1982) evaluated perceived innovation characteristics in a meta-analysis of seventy-five articles dealing with technology adoption, including those incorporating attributes from the diffusion of innovations model, to determine which attributes were 
most consistently related to an innovation's adoption. The three perceived innovation attributes that they found most relevant to one's decision were relative advantage, compatibility, and complexity (Tornatzky \& Klein, 1982). While observability or trialability were not shown to have many significant associations with innovation adoption, they are worth evaluating since the effects might vary for newer, digital, technologies.

$\mathrm{H} 2$ : An innovation perceived as having a greater degree of compatibility correlates with one's increased interest in purchasing a specific new technology. H3: An innovation perceived as having a greater degree of visibility correlates with one's increased interest in purchasing a specific new technology. H4: An innovation perceived as having a greater degree of trialability correlates with one's increased interest in purchasing a specific new technology. Davis (1989) took the research of Tornatzky and Klein (1982) into account and originally delineated the key components of the technology acceptance model, which included measures of perceived usefulness and perceived ease of use. Davis found that perceived usefulness was more highly associated with future adoption than perceived ease of use (Davis, 1989; Venkatesh, Morris, Davis, \& Davis, 2003; Ward, 2013). Perceived usefulness is defined as the "extent [to which an individual believes an innovation] will help them perform their job better" (Davis, 1989, p. 320). Perceived usefulness varies from relative advantage in that the latter is comparative, whereas the former relates only to the technology in question. The measurements for these constructs are similar enough that my research considers the two constructs indistinguishable for the 
purposes of hypothesis testing; scales for the two overlap in the precise wording of four different items asked (Davis, 1989; Moore \& Benbasat, 1991).

Perceived ease of use is defined by how "free of effort" using "a particular [innovation]" will be (Davis, 1989, p. 320) and, while slightly different, is similar to the construct of complexity, identified both in the diffusion of innovations model and in earlier technology acceptance models. While greater perceived ease of use is still related to greater innovation adoption rates, a certain degree of increased complexity often contributes to the level of "fun" that an innovation seems to have (Davis, 1989). For example, a game that is perceived as too easy would likely lose a viewer's interest and not be sustainably "fun." Intrinsic motivation is often the most powerful in determining how an individual perceives "fun" (Carroll \& Thomas, 1988). Following from Davis' (1989) results, I pose $\mathrm{H} 5$ and $\mathrm{H} 6$ about relative advantage/ perceived usefulness and perceived ease of use.

H5: An innovation perceived as having a greater amount of relative advantage/ perceived usefulness correlates with one's increased interest in purchasing a specific new technology.

H6: Digital technologies that seem easy to use are positively correlated with an individual's interest in purchasing a specific new technology.

New technologies have been shifting to accommodate individuals instead of entire societies and, with increased interpersonal communication due to computer-mediated technology, newer technologies have been re-invented for personal, instead of workrelated, use (Vannoy \& Palvia, 2010). For example, technologies such as text messaging and file sharing have shifted from being used for industrial applications to being used 
primarily for interpersonal communication (Vannoy \& Palvia, 2010). In recent technologies, the user plays "an increasingly interactive and central role in issues of design, development, and marketing," thus creating a need for this extension of the original technology acceptance model (Vannoy \& Palvia, 2010, p. 151). For example, "smart" refrigerators can be programmed to "order what you need, when you need it" and "smart" robots can be programmed to "navigate past obstacles, read bedtime stories, [or] play your favorite tunes or podcasts" (Meet LG ThinQ, 2018). The purpose of researching constructs that are outside of the original technology acceptance model, like customizability, helps "to better understand and predict adoption intentions of new media technology" (Baaren, Wijngaert, and Huizer, 2013, p. 85). With the recent increase in technological innovations that are intentionally configured to be customized by the product's user so that it will be more compatible with the user's situation, I have developed $\mathrm{H} 7$ with the hope that the construct of customizability can be incorporated into future models of technology adoption if it does, in fact, lead to increased interest in "smart" technology adoption.

H7: One's opinion on customizability is positively correlated with one's interest in purchasing a specific new technology.

While an individual's perceptions of technology attributes are, no doubt, integral to one's purchasing decision, it is also worth considering how one's opinion of privacy and security risks play a role in their decision. The World Economic Forum listed four technological issues considered to be in the top thirty of "global risks of highest concern for doing business" (World Economic Forum, 2017). These technology risks include the possibility of cyberattacks, data fraud or theft, misuse of technologies, and critical 
information infrastructure breakdown. In the United States, "cyberattacks," "misuse of technology," and "data fraud or theft" were ranked second, third, and fifth, respectively, within this list, emphasizing the potential impact of this on individual opinions about new digital, internet-connected, technologies (World Economic Forum, 2017). In 2017, research showed that $64 \%$ of Americans "have personally experienced a major data breach" and that almost half of those surveyed felt that their personal information is less secure than it was five years prior (Smith, 2017, para. 4). While discussing the overload of information with technological innovations, boyd (2017) notes how society must now "strategically think about how others want to manipulate our systems to do harm and cause chaos" (para. 28). With the increase in cybercrime and the likelihood of device security issues potentially affecting individuals' opinions about new technology, I have developed H8.

H8: Greater privacy concerns about new technologies are negatively correlated with one's interest in purchasing a specific new technology.

This study hopes to further the understanding of general factors and attributes that individuals might find most influential in determining whether or not to adopt a digital, internet-connected, technology. To summarize, I have included Figure 1 to represent the relationships between constructs in my hypotheses and research questions. 


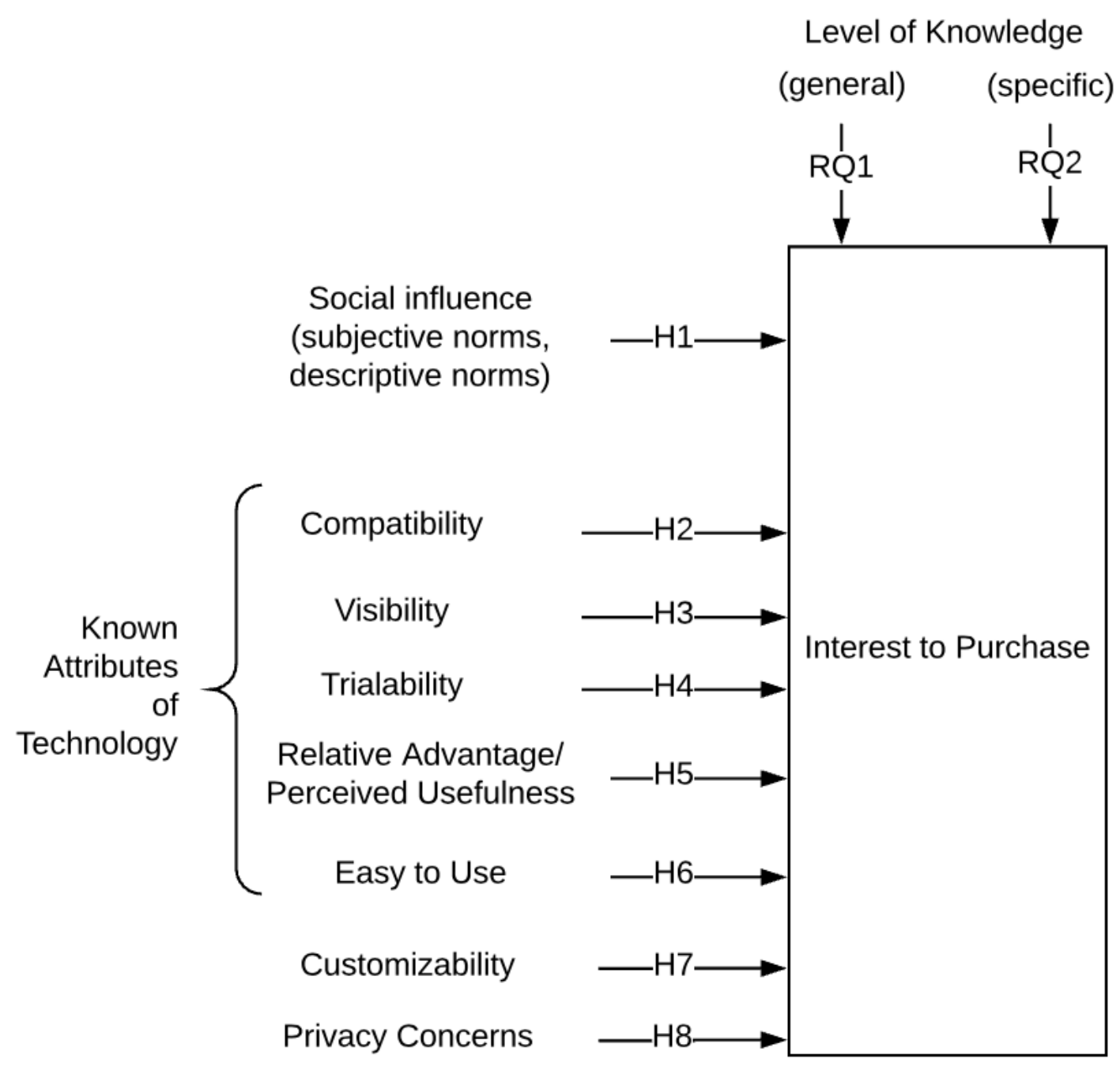

Figure 1. Hypothesized relationships between constructs. 


\section{Method}

\section{Participants}

Participants were selected by a convenience sample from communication courses at a public university in the Pacific Northwest. While 133 survey responses were received, twelve response sets were either left blank or eliminated for ineligibility and five responses were eliminated for showing response set, which brought the total eligible participant count to 116 participants. Participants were given an informed consent form and, upon understanding, chose whether to complete a survey developed online in Qualtrics (see Appendix A). All individuals who participated received extra credit. Participants who were ineligible to complete the survey or who chose not to complete it were given an alternative opportunity for extra credit. In order to ensure that participants did not already own a "smart" refrigerator and that the survey measured intention to adopt, I asked "Have you ever purchased or owned a smart refrigerator for your personal use?" at the end of my survey. Data from one participant was considered ineligible and discarded because they already owned a "smart" refrigerator. This study procedure complied with all requirements for human subject research and was approved by the Institutional Review Board before data collection began (see Appendix B).

Participants included 35 men (30.2\%) and 78 women (67.2\%) equaling a total of 116 participants between the ages of 19 and $49(M=25.7, S D=5.4)$. The racial variation among participants included African-American $(n=11 ; 9.5 \%)$, Asian-American $(n=13$; 11.2\%), Hispanic or Latino $(n=14 ; 12.1 \%)$, White $(n=68 ; 58.6 \%)$, or Other $(n=9$; $7.7 \%)$.

New technology awareness is often a precursor to technology attribute 
consideration and adoption within most adoption models (Manning, Bearden, \& Madden, 1995). To appropriately measure innovation attribute perceptions before adoption, it is important not only to ask individuals about a technology that they do not yet use, but also important for individuals to have a general awareness of that technology. Of the 116 participants that I surveyed, $63.8 \%(n=74)$ were aware of "smart" refrigerators, while $35.3 \%(n=41)$ were not.

\section{Measures}

Research on public opinion of new, digital technologies is difficult given the nature of the diffusion of innovations model and how different segments of the population will be aware of and knowledgeable about different innovations at different times. I presented participants with a short informational paragraph about a "smart" refrigerator and asked them to consider this new digital technology appliance during the duration of the survey.

Want a refrigerator that will recommend recipes, create shopping lists and play music for your meal? A "smart" refrigerator can. Experience a refrigerator... which lets you create and share shopping lists between your smartphone and refrigerator, or check on the contents of your refrigerator, anytime, anywhere. Internal cameras give you real-time updates of what's in the fridge. Get step-bystep instructions to make your favorite recipes. Get an alert when groceries are about to expire and order more right from your fridge. Enjoy peace of mind with a fridge that knows how to optimize settings so that it can be even more energy efficient. (adapted from Meet LG ThinQ, 2018)

I chose "smart" refrigerators as the digital technology because of the high cost of this 
appliance, the low possibility that my participant group will already own it, and the chance that my participant group will consider it in the future when making appliance purchases.

Level of knowledge (about new inventions and technologies). One's level of understanding about a specific new technology can vary greatly from one technology to the next, given the wide range of existing innovations. Past research has measured knowledge about innovations qualitatively by asking specifics about what participants know about a given technology (Miller, 2004). Since I am looking at newer, digital, technology, I used two sets of questions about technology that evaluated individuals' level of general knowledge about technology and about their specific knowledge of "smart" refrigerators.

To measure one's level of general technology knowledge, I used a scale developed by Hosseini and Kamal (2012). I have asked respondents to reply on a scale of $1=$ strongly disagree to $7=$ strongly agree. This eleven-item scale includes statements such as "I know how to solve my own technical problems," "I keep up with important new technologies," and "I have had sufficient opportunities to work with different technologies." These items produced a Cronbach's alpha of $\alpha=.88$.

To measure one's level of specific technology knowledge, I used another scale developed by Hosseini and Kamal (2012). Also on a scale of $1=$ strongly disagree to $7=$ strongly agree, participants were asked to respond to three items according to their opinions on statements such as "I could learn how to use specific software related to smart refrigerators." For these statements, I calculated a Cronbach's alpha of $\alpha=.82$. 
Social influence. I asked participants to answer questions related to their social group by having them "think of five people in [their] social group that [they] have talked with the most often in the past six months," in accordance with research done by Valente evaluating interpersonal influence (Valente, 1997). In order to create a variable representing subjective norms, I combined (by multiplying) the normative support (i.e. "How many of these people have encouraged (or would encourage) you to use a smart refrigerator?") with one's motivation to comply (i.e. " How much do you care about the opinions of these five people regarding their opinion about new technologies?" (Ajzen, 2013). This created a variable with a numerical value on a scale from 0 to 25 , with higher numbers representing stronger normative support. This number represents how strongly the opinions and advice of one's friends affect one's decisions.

As a second measure of social influence, I also asked about descriptive norms by asking "From how many of these people have you received (or would you receive) technology-related advice?." I also asked participants "How many of these people own a smart refrigerator?."

Valued attributes. Participants were asked about their perception of technology attributes, such as relative advantage, compatibility, perceived ease of use, perceived usefulness, visibility, and trialability.

Valued attribute: Relative advantage/ usefulness. The scale for relative advantage was originally developed by Moore and Benbasat (1991). Responses were recorded on a scale of $1=$ strongly disagree to $7=$ strongly agree to be compatible with other scales in my survey. In the original scale, "PWS" stands for a "personal work station", which is the specific technology that had been evaluated. Since "it is believed 
that [all of the measures] could be easily reworded by substituting the names of different IT innovations, though additional checks for validity and reliability would be prudent after rewording," for my survey, I have replaced "PWS" with "a smart refrigerator," (Moore \& Benbasat, 1991, p. 211). Additionally, I have adjusted questions to be appropriate for a personal appliance that one does not yet own, such as using "in my home life" or "those surrounding me" instead of "at work" or "my superiors," respectively, and adjusting verb choice.

Original statements measuring relative advantage included "Using a PWS enables me to accomplish tasks more quickly" or "Using a PWS improves the quality of the work I do." In adjusting word choice to be more appropriate, I changed these statements to "Using a smart refrigerator would enable me to accomplish tasks more quickly" and "Using a smart refrigerator would improve the quality of my home life."

In order to evaluate how individuals perceive the usefulness of specific technologies in their daily lives, I have also adapted scale items from the "perceived usefulness" developed by Davis (1989, p. 340). All items were originally measured on a 7-point scale of $1=$ extremely likely to $7=$ extremely unlikely. To remain consistent with other scales in my survey, I adjusted this scale to range from $1=$ strongly disagree to $7=$ strongly agree. After adjusting items to be specific to "a smart refrigerator" (instead of "CHARTMASTER) and to "at home" (instead of "in my job; Davis, 1989, p. 331), four scale items for relative advantage and perceived usefulness were identical. An exploratory factor analysis showed that items from both scales were measuring the same construct. Therefore, for my analysis, I used all responses from the relative advantage scale, as these were asked first in my survey instrument and avoided any chance of 
participant priming, and included the two unique questions adapted from Davis' scale measuring perceived usefulness: "Using a smart refrigerator would improve my performance at home" and "I would find a smart refrigerator useful in my life." This created a ten-item scale measuring a construct of relative advantage/ perceived usefulness, which had a Cronbach's alpha of $\alpha=.97$. I aggregated all ten items into one measure.

Valued attribute: compatibility. Compatibility, like relative advantage, is one of the attributes that individuals often consider when choosing whether or not to purchase a new technology, like a "smart" refrigerator (Moore \& Benbasat, 1991). The compatibility scale was also originally developed by Moore and Benbasat (Moore \& Benbasat, 1991). Similarly, responses were recorded on a scale of $1=$ strongly disagree to $7=$ strongly agree to be compatible with other scales in my survey. As with items from Moore and Benbasat's (1991) scale for relative advantage, similar adjustments in word choice were made to make the compatibility scale appropriate for this survey.

An original statement measuring compatibility was "Using a PWS is compatible with all aspects of my work." I adjusted this statement, and others, as appropriate. For example, I changed the previous statement to "Using a smart refrigerator would be compatible with all aspects of my home life." The Cronbach's alpha that I calculated for compatibility is $\alpha=.93$. I aggregated all four items for compatibility into one measure.

Valued attribute: Perceived ease of use of technology. To measure how "easy" individuals perceive using technology to be, I have adapted scale items for "perceived ease of use" developed by Davis (1989, p. 340). Similar to how I adjusted Davis' (1989) scale for "perceived usefulness," the original scale uses the technology "CHART- 
MASTER," which I have replaced with "a smart refrigerator." For example, "Learning to operate CHART-MASTER would be easy for me" has been changed to "Learning to operate a smart refrigerator would be easy for me." Otherwise, all scale items are identical. Answers were originally recorded on an interval scale from $1=$ extremely likely to 7 = extremely unlikely. I have adjusted this scale to range from $1=$ strongly disagree to 7 = strongly agree to be better suited to each item and also consistent with my survey. The Cronbach's alpha for perceived ease of use is $\alpha=.93$. Subsequently, I aggregated all six items into one measure.

Valued attribute: Visibility. Moore and Benbasat (1991) developed a scale for "Observability" that included two combined scales of "Result Demonstrability" and "Visibility." Despite the higher reliability of the combined scales, I decided to only use Moore and Benbasat's scale for "Visibility," as this seemed to better measure one's observation of an innovation in use. "Result Demonstrability," which appeared to measure how easily a technology could be demonstrated, seemed so closely tied to trialability that I felt its addition to the "Visibility" scale would produce responses not specific to one's observability of an innovation. Statements from the "Visibility" scale were adjusted to be specific to "smart" refrigerators and were measured on a scale of $1=$ strongly disagree to $7=$ strongly agree. The "Visibility" scale includes statements such as "I will be able to see what others do using their smart refrigerators" and "It will be easy for me to observe others using smart refrigerators at home appliance stores." Before finding the scale's reliability and then aggregating all four responses into one measure, I reverse coded when appropriate so that greater number responses represented greater agreement with each statement. The "Visibility" scale produced a Cronbach's alpha of $\alpha$ 
$=.60$.

Valued attribute: Trialability. The scale that was used to measure trialability was developed by Benbasat and Moore (1991). Statements from this five-item scale were measured on a scale of $1=$ strongly disagree to $7=$ strongly agree. The "Trialability" measure included statements, which I altered to be specific to "smart" refrigerators, such as "I will have a great deal of opportunity to try various smart refrigerators at home appliance stores" and "I will be able to use a smart refrigerator on a trial basis long enough to see what it can do." Before aggregating the five responses for trialability into a single measure, this scale resulted in a Cronbach's alpha of $\alpha=.78$.

Opinion on customizability. Guilabert and Donthu (2003) developed a six-item scale called the "Customer Customization Sensitivity (CCS) Scale" that measures "whether potential customers will accept customization or not" (Blecker, Friedrich, Kaluza, Abdelkafi, \& Kreutler, p. 24). Guilabert and Donthu (2003) recognized the importance of identifying a specific technology while collecting individuals' opinions about customizability "since different people might have varying needs for customized products and services" (p. 1). In adjusting this scale, I have replaced blanks with "a smart refrigerator," which is the specific technology that I am asking participants to consider throughout the majority of my survey. To make the scale more relatable to this particular study, I have replaced "products/ services" with "digital technology products, like a smart refrigerator." For example, instead of "In general, customized products/ services meet my needs better than standard ones," I have adjusted this item to "In general, a customized smart refrigerator would probably meet my needs better than a standard one." I used a Likert scale from $1=$ strongly disagree to $7=$ strongly agree to conform to other scales in 
my survey. I computed an acceptable Cronbach's alpha of $\alpha=.80$ and aggregated all six scale items to produce one measure for customizability.

Privacy concerns. A four-item scale measuring individuals' concern with privacy was developed by McKnight, Lankton, and Tripp (2010). Participants were asked to respond to statements on a scale from $1=$ not at all concerned to $5=$ extremely concerned. Items were adjusted to be specific to "smart" refrigerators and included statements such as "I am concerned that the information I give to my smart refrigerator could be misused" and "I am concerned that a person can find private information about me by using or hacking into my smart refrigerator." Cronbach's alpha was measured at $\alpha$ $=.93$. Subsequently, all four items were aggregated into one measure.

Intent to purchase. Participants were asked to respond on a scale from $1=$ strongly disagree to $7=$ strongly agree to two statements about their intent to purchase new technology, specifically "smart" refrigerators. Participants' responses to the first statement "I would consider purchasing a smart refrigerator for my personal use" were used to evaluate the relationships with technology attributes in my hypotheses. To assess participants' opinions when cost is not an issue, I also asked for responses to the statement "If I were to win a smart refrigerator, I would choose to use it." I ran post-hoc correlation tests with responses to the latter statement to determine if participants' attitudes toward technology attributes change when cost is not a factor.

Demographics and technology interest. Heinz (2013) adapted five items that evaluate interest in technology adoption. Heinz's participants answered on a scale of $1=$ strongly agree to $5=$ strongly disagree but to maintain consistency throughout my survey, I have asked respondents to reply on a scale of $1=$ strongly disagree to $7=$ 
strongly agree. I have adjusted this scale to focus specifically on new technology, like "smart" refrigerators. For example, I have changed "I don't care to know more about new technology" to "I don't care to know more about new technologies, like smart refrigerators," I reverse coded three statements appropriately after collecting data so that a higher response number represented greater interest in technology adoption. Heinz reported a Cronbach's alpha of $\alpha=.79$ for these five items (Heinz, 2013, p. 28). Additionally, I added an extra item asking about a participant's interest in adopting a "smart" refrigerator, specifically: "If cost were not an issue, I would consider purchasing a smart refrigerator." I calculated a Cronbach's alpha of $\alpha=.79$ for these six items. All five items were aggregated into one measure to gauge interest in smart refrigerators, as a technology.

Additionally, the survey asked about participant demographics such as age, gender, and race. To understand the general socioeconomic background of participants, two questions were asked which have been developed by the U.S. Department of Housing and Urban Development (Blake, Kellerson, \& Simic, 2007): "How many people (adults and children) including yourself lived in the home in which you were raised?" and "How many bedrooms were in the home in which you were raised?." Upon receiving responses, I created a new variable that represented people per bedroom; lower numbers represented higher socioeconomic status. I asked participants to respond on a scale from $1=$ strongly disagree to $7=$ strongly agree regarding their opinion on how well their parents keep up with new technologies. Additionally, participants were asked to share anything else that they felt was important to include regarding technology adoption. 
Analysis

Data for all hypotheses were collected from a survey administered in February 2019. All hypotheses and research questions were evaluated by using correlation tests. For all hypotheses, an alpha level of .05 was set a priori. After collecting data, I ran a multiple linear regression to determine the effect that each element of my model has on technology purchasing decision. 


\section{Chapter Four: Results}

While about a third of the 116 eligible participants surveyed had never heard of a "smart" refrigerator $(35.5 \%, n=41), 38.0 \%(n=44)$ of participants agreed (strongly agreed, agreed, or somewhat agreed) that they would purchase one $(M=6.79, S D=$ 1.74). A slightly higher percentage $(53 \% ; n=62)$ of participants agreed (somewhat agreed, agreed, strongly agreed), on average, that they were interested in new technology, like smart refrigerators $(M=5.05, S D=1.01)$. Sometimes parental technology use affects one's interest in and awareness of new technologies and almost 40\% (38.7\%; $n=$ 45) of participants agreed that their parents kept up with important new technologies ( $M$ $=6.47, S D=1.73)$. Despite this $79.4 \%(n=92)$ of participants were interested in using a "smart" refrigerator if cost was not a factor $(M=8.63, S D=1.59)$.

It appeared that one's level of general technology knowledge did correlate with one's intentions to adopt a new technology, while specific technology knowledge did not. In RQ1 and RQ2, I explored how one's level of general technology knowledge and specific technology knowledge, respectively, correlated with one's interest in purchasing new technology, represented by a "smart" refrigerator in this study. Using a Pearson's $r$ correlation test for RQ1, I found that there is a statistically significant positive correlation between one's level of knowledge about technology in general $(M=4.94, S D=0.93)$ and one's interest in purchasing $(M=3.79, S D=1.74)$ a specific new technology, $r(113)=$ $.246, p=.008$. However, also using a Pearson's $r$ correlation test for RQ2, I found that there is not a statistically significant positive correlation between one's level of knowledge about a specific technology $(M=5.13, S D=1.27)$ and one's interest in purchasing that specific new technology, $r(113)=.092, p=.33$. This shows how one's 
level of specific knowledge about technology did not statistically significantly relate to one's interest in purchasing a new technology, but that one's general knowledge about technology did.

\begin{tabular}{lcc}
\hline \multicolumn{1}{c}{ Attributes } & Mean & SD \\
\hline DOI and TAM Attributes: & & \\
Relative Advantage/ Perceived Usefulness $^{\text {a }}$ & 4.3 & 1.4 \\
Compatibility $^{\text {a }}$ & 4.2 & 1.4 \\
Ease of Use $^{\text {a }}$ & 5.5 & 1.0 \\
Visibility $^{\text {a }}$ & 3.7 & 0.9 \\
Trialability $^{\text {a }}$ & 4.2 & 1.1 \\
Other factors: $_{\text {Technology Knowledge (General) }}{ }^{\mathrm{a}}$ & & \\
Technology Knowledge (Specific) $^{\mathrm{a}}$ & 4.9 & 0.9 \\
Social Influence: Subjective Norms $^{\mathrm{b}}$ & 5.1 & 1.3 \\
Social Influence: Descriptive Norms $^{\mathrm{c}}$ & 2.0 & 3.9 \\
Customizability $^{\mathrm{a}}$ & 0.6 & 1.0 \\
Privacy Concerns $^{\mathrm{d}}$ & 4.5 & 1.1 \\
\hline
\end{tabular}

${ }^{a}$ Relative advantage/ perceived usefulness, compatibility, visibility, trialability, technology knowledge (general and specific), and customizability theoretically range from 1-7

${ }^{\mathrm{b}}$ Social Influence: Subjective Norms theoretically ranges from 0-25

${ }^{\mathrm{c}}$ Social Influence: Descriptive Norms theoretically ranges from 0-5

${ }^{\mathrm{d}}$ Privacy Concerns theoretically range from 1-5

Table 1. Means and standard deviations of technology attributes

Interestingly, $91.3 \%(n=105)$ of participants said that they had at least one individual from whom them would receive technology-related advice. $\mathrm{H} 1$ evaluates whether or not one's exposure to technology via social influence correlates with one's interest in purchasing a specific technology. By using a Pearson's $r$ correlation test looking at the relationship between social influence (both subjective $[M=2.00, S D=$ 3.94] and descriptive norms $[M=0.58, S D=1.04])$ and one's interest in purchasing $(M=$ $3.79, S D=1.74)$, I found that there is a statistically significant positive correlation for both subjective, $r(112)=.309, p=.001$ and descriptive norms $r(112)=.328, p<.001$, 
supporting the hypothesis that one's exposure to technology through social interactions positively correlates with one's interest in technology purchase. As a whole, it appears that social interaction is a statistically correlated with one's decision to purchase new technology.

I also ran a Pearson's $r$ correlation test for $\mathrm{H} 2$ to evaluate the relationship between one's perception of compatibility that an innovation has with one's life and one's interest in purchasing that specific technological innovation. I found that one's perception of an innovation's higher degree of compatibility with their life $(M=4.20, S D=1.42)$ positively correlated with one's increased interest in purchasing a specific new technology, $r(113)=.550, p<0.001$, thus supporting H2. Therefore, if an individual feels that an innovation fits well with their lifestyle, it is likely that they will be more willing to use that innovation in the future.

$\mathrm{H} 3$ predicted that one's perception of an innovation having a greater degree of visibility correlated with one's increased interest in purchasing a specific new technology. Using a Pearson's $r$ correlation test, I found that H3 was supported. Individuals' perceptions of an innovation's visibility $(M=3.68, S D=0.89)$ did positively correlate with one's interest in purchasing, $r(113)=.327, p<0.001$. More simply, if individuals felt that an innovation was observable in their daily life, or when they sought it out, they would be more likely to purchase it in the future.

In order to evaluate whether or not one's perceived ability to try an innovation is correlated with one's interest in purchasing a specific technology for H4, I ran a Pearson's $r$ correlation test. H4 was supported. As one's perception of an innovation's trialability ( $M$ $=4.19, S D=1.10)$ increased, so did one's interest in purchasing a specific new 
technology, $r(113)=.260, p=.005$. In other words, if individuals feel that they have opportunities to experiment with or try an innovation before purchasing, they will be more likely to consider purchasing that innovation.

In addition to trialability, I evaluated whether or not various attributes that an individual perceived of a new technology correlated with their interest in purchasing. For H5, I predicted that there would be a positive correlation between one's opinion of an innovation having higher relative advantage/ perceived usefulness and one's increased interest in purchasing a specific new technology. Using a Pearson's $r$ correlation test for H5, I found that there is a statistically significant positive correlation between one's perception about an innovation's relative advantage/ perceived usefulness $(M=4.28, S D$ $=1.37)$ and one's interest in purchasing $(M=3.79, S D=1.74)$ a specific new technology, $r(113)=.626, p<0.001$, supporting H5. One is more likely to want to purchase a new technology if they feel that it would make their lifestyle more simple or effective.

In addition to usefulness, I wanted to know if one's perception of a technology's ease of use correlated with one's interest in purchasing that technology (H6). A Pearson's $r$ correlation test showed that H6 was supported and that ease of use $(M=5.52, S D=$ 0.96) was positively correlated with interest in purchasing a specific new technology, $r(113)=.246, p=0.008$. Therefore, if one thinks that an innovation is easy to use, they are more likely to show interest in purchasing that innovative technology.

For H7, I explored whether one's opinion about customizability for a technological innovation correlated with one's interest in purchasing a specific new technology. H7 was supported, as I found that the greater customizability individuals felt that a new technology had $(M=4.54, S D=1.11)$, the more interest they showed toward 
purchasing that specific new technology, $r(113)=.609, p<0.001$.

Additionally, I felt that it was important to find if there was a relationship between interest in purchasing a new technology and the privacy concerns that individuals had regarding technology (H8). A Pearson's $r$ correlation test did not show a significant relationship between privacy concerns $(M=2.70, S D=1.20)$ and interest in purchasing a specific new technology, $r(113)=-.09, p=0.359$, which meant that $\mathrm{H} 8$ was not supported. Individuals who were not interested in purchasing a new technology did not necessarily feel this way because of any concerns they might have felt about a technology's security.

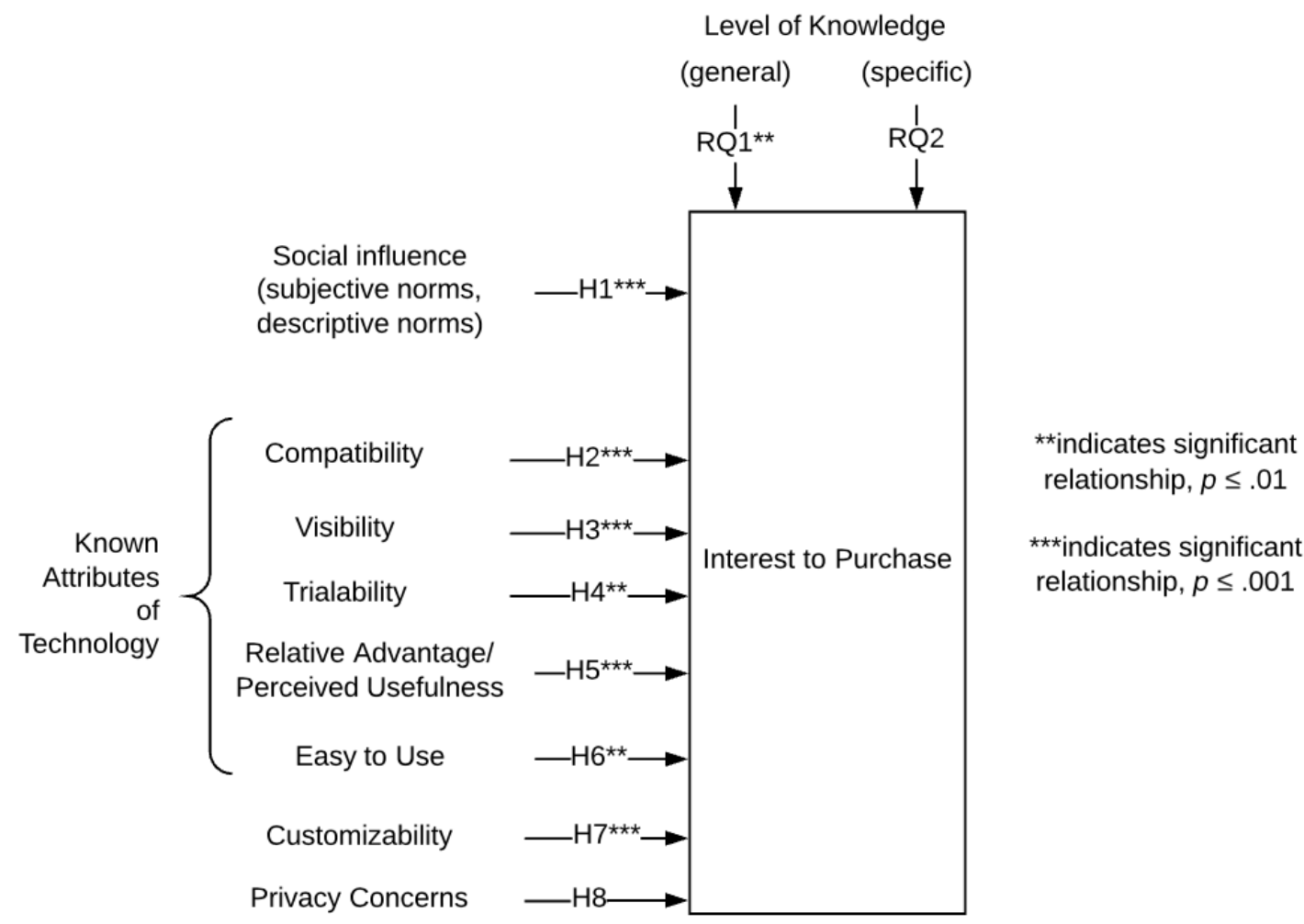

Figure 2. Results of relationships between constructs.

A summary of these findings is shown in Figure 2. Additionally, correlations of each 
variable with each other are shown in Table 2 to explain how the attributes evaluated overlapped. 


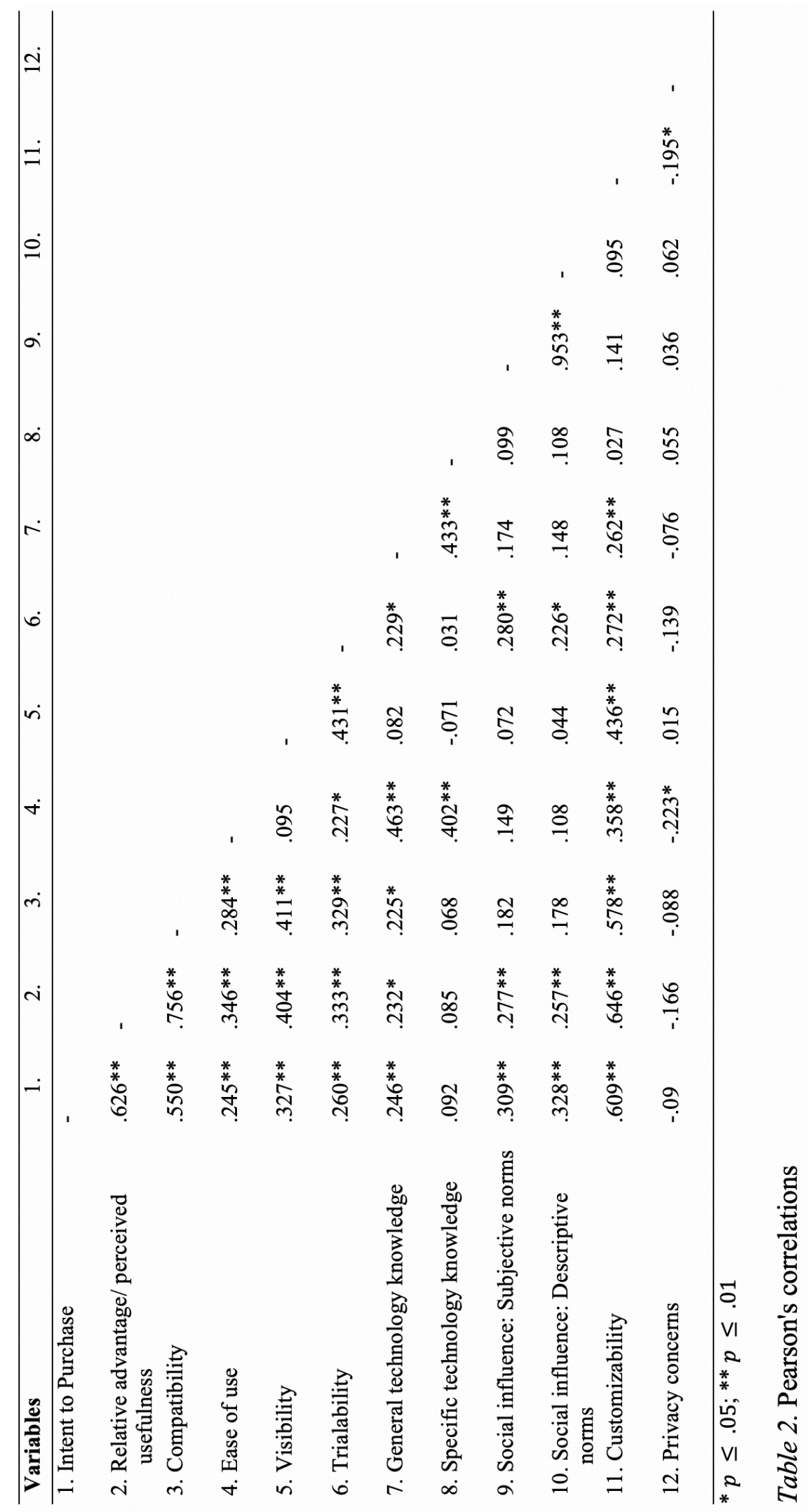


A linear regression test reveals that the combination of attributes measured in my research predicts one's interest in purchasing a new, "smart" technology.

\begin{tabular}{|c|c|c|c|c|c|c|}
\hline & \multicolumn{3}{|c|}{ Model 1} & \multicolumn{3}{|c|}{ Model 2} \\
\hline $\begin{array}{l}\text { DOI and TAM } \\
\text { attributes: }\end{array}$ & $\boldsymbol{\beta}$ & $t$ & $p$ & $\boldsymbol{\beta}$ & $t$ & $p$ \\
\hline $\begin{array}{l}\text { Relative advantage/ } \\
\text { perceived usefulness }\end{array}$ & 466 & 3.923 & $.000^{* * *}$ & 249 & 2.053 & $.043 *$ \\
\hline Compatibility & .154 & 1.322 & .189 & .097 & 0.887 & .377 \\
\hline Ease of use & .030 & 0.379 & .706 & -.056 & -0.639 & .524 \\
\hline Visibility & .060 & 0.683 & .496 & .018 & 0.218 & .828 \\
\hline Trialability & .019 & 0.228 & .820 & 011 & 0.131 & .896 \\
\hline $\begin{array}{l}\text { Other factors: } \\
\text { General tech. } \\
\text { knowledge }\end{array}$ & - & - & - & .055 & 0.656 & .513 \\
\hline $\begin{array}{l}\text { Specific tech. } \\
\text { knowledge }\end{array}$ & - & - & - & .032 & 0.395 & 694 \\
\hline $\begin{array}{l}\text { Social influence: } \\
\text { Subjective norms }\end{array}$ & - & - & - & -.363 & -1.544 & .126 \\
\hline $\begin{array}{l}\text { Social influence: } \\
\text { Descriptive norms }\end{array}$ & - & - & - & .549 & 2.367 & $.020^{*}$ \\
\hline Customizability & - & - & - & .387 & 3.881 & $.000 * * *$ \\
\hline Privacy concerns & - & - & - & .012 & .169 & .866 \\
\hline Model & \multicolumn{3}{|c|}{$\begin{array}{c}F(5,113)=14.83, p<.001, \\
R^{2}=.38\end{array}$} & \multicolumn{3}{|c|}{$\begin{array}{c}F(11,113)=10.16, p<.001, \\
R^{2}=.47\end{array}$} \\
\hline
\end{tabular}

$* p \leq .05 ; * * p \leq .01 ; * * * p \leq .001$

Table 3. Multiple linear regression predicting intention to purchase a new technology.

In running this regression, one's intention to purchase was the dependent variable. In the first model, independent variables included one's perception of a technology's relative advantage/ perceived usefulness, compatibility, ease of use, visibility, and trialability. While evaluating intention to purchase using attributes from previous models, relative advantage/ perceived usefulness, compatibility, ease of use, visibility, and trialability 
account for $38.0 \%$ of the variance.

The regression equation of Model 2, with the inclusion of customizability, one's general and specific technology knowledge, one's influence from others, and one's opinion about a technology's security was statistically significant, $\mathrm{F}(11,113)=10.164, p$ $<.001, \mathrm{R}^{2}=.471$. The addition of these factors explains $47.1 \%(\Delta=9.1 \%)$ of the variance. While the predictors of relative advantage/ perceived usefulness, $\beta=.249, S E=$ $.154, p=.043$, social influence (specifically, descriptive norms), $\beta=.549, S E=.386, p=$ .020 , and customizability, $\beta=.387, S E=.157, p<.001$, were statistically significant, no other predictors were (see Table 3). This emphasizes the importance that social influence and customizability play during one's decision-making process regarding the purchasing of smart technology.

\section{Post-hoc Correlations}

In running all hypotheses again with the independent variable of "intention to use if won" ( $M=5.63, S D=1.59)$ instead of "intention to purchase," Pearson's $r$ correlation tests revealed that relative advantage/ usefulness, compatibility, ease of use, customizability, and privacy concerns were significantly correlated with one's "intention to use if won." Specifically, using a Pearson's $r$ correlation test, I found that one's opinion of a "smart" technology's relative advantage/ usefulness $(M=4.28, S D=1.37)$ was statistically significantly correlated with one's interest in using a "smart" technology if cost was not a factor, $r(113)=.383, p<.001$. Compatibility $(M=4.20, S D=1.42)$ is also statistically significantly correlated with one's interest in using a "smart" technology if won, $r(114)=.321, p<.001$; If individuals feel that a free "smart" technology is more likely to fit with their lifestyle than whatever they currently use to fulfill a similar 
purpose, they are more likely to use that new device. A Pearson's $r$ correlation test showed that one's perception of a free "smart" technology's simplicity (ease of use) is high $(M=5.52, S D=0.96)$, one is more likely to use that product, $r(114)=.232, p=$ .012. Additionally, customizability $(M=4.54, S D=1.11)$ was also considered strongly significantly correlated with one's decision to use a "smart" technology if won, $r(114)=$ $.398, p<.001$. Interestingly, privacy concerns $(M=2.70, S D=1.20)$ were negatively correlated with one's decision to use a new, "smart" technology if won, $r(114)=-.206, p$ $=.027$; if individuals felt that the security surrounding a smart technology was large, they would be less likely to use a new technology, even if it was free.

Neither one's level of knowledge (general $[M=4.94, S D=0.93], r(114)=.043, p$ $=.644$; specific $[M=5.13, S D=1.27], r(114)=.023, p=.810)$, nor social influence (subjective norms $[M=2.00, S D=3.94], r(113)=.130, p=.165$; nor descriptive norms $[M=0.58, S D=1.04], r(113)=.116, p=.218)$, nor perception of a technology's visibility $([M=3.68, S D=0.89], r(114)=.055, p=.560)$, nor trialability $([M=4.19, S D$ $=1.10], r(114)=.139, p=.138)$ were significantly correlated with one's intention to use a "smart" new technology if won. 


\section{Chapter Five: Discussion}

Technology adoption is a complex process involving individuals' perceptions of technology attributes. Communication about a new technology contributes to the formation of opinions and perceptions of these attributes. Understanding how individuals decide to purchase and use "smart" technologies will not only improve the design process for future devices but will also influence the objectives of current technology marketing efforts. By asking individuals about a variety of technology attributes, I have uncovered which attributes individuals might find important in their decisions to adopt "smart" devices and why that might be true.

I have chosen to use attributes described in both the diffusion of innovations model and technology acceptance models for this study, as I feel that both models have factors that would be worth considering while evaluating newer, internet-connected, technology. While the diffusion of innovations theory is considered the seminal research on technology adoption, technology acceptance models are commonly used to evaluate the adoption of information technology, which would likely encompass internetconnected devices (Dadayan \& Ferro, 2005). The diffusion of innovations model states that relative advantage, compatibility, observability, and trialability account for over half of the variance for innovation adoption (Rogers, 2003); Technology acceptance models explore additional factors that might account for some of the remaining variance. Many variations of adoption models have been developed over time and it would be difficult, if not impossible, to determine which models (or combination of models) would be the best fit for research evaluating the adoption of internet-connected devices.

It is worth noting how one's perception about their level of knowledge about 
technology, in general, was statistically significantly related to their intent to purchase a smart refrigerator, whereas one's perception about their level of knowledge about a smart refrigerator was not. Individuals who feel more confident about their general technology knowledge might be more inclined to purchase a new device, regardless of how confident they are with their knowledge about that specific device. Not many individuals expressed awareness of smart refrigerators, so it is possible that one's level of knowledge about a specific technology matters more when individuals are acutely aware of that technology and have already formed opinions about that technology's attributes. Technology changes rapidly, and the types of information that individuals might know about technologies will shift over time.

While gaining knowledge about new technologies and by discussing them with others, a variety of attributes have been identified in past research that most strongly relate to one's decision to adopt. As Tornatzky and Klein (1982) found in their research, relative advantage and compatibility are two of the most influential attributes that one considers during the adoption process (Tornatzky \& Klein, 1982). My research also shows that both of these perceived attributes (and usefulness which, in effect, was one and the same with relative advantage) play a strong role in one's decision to purchase $(\mathrm{H} 5, \mathrm{H} 2)$; while relative advantage/ usefulness was more strongly correlated with one's decision to adopt, compatibility followed closely behind. In the regression model, relative advantage/ usefulness was shown to be significant in one's decision to purchase.

In Davis' (1989) research, he also found that one's perception of an innovation's usefulness had a significant impact on one's intention to adopt (Davis, 1989; Ward, 2013). It is possible that individuals become aware of certain technology products 
because of an interest in fulfilling unmet needs in one's life. For example, if an individual hears that a "smart" refrigerator can automatically order expired items, that individual might realize the utility of owning a "smart" refrigerator since it would eliminate their need to constantly search their refrigerator for items that have gone bad on a weekly basis (Meet LG ThinQ, 2018). Those who are rarely home to clean or those who have pets that shed might find the usefulness of a vacuuming robot higher than someone who has no pets or works from home, thus increasing their perception of a vacuuming robot's usefulness (Rae, 2019).

Among the attributes evaluated in my research, ease of use (H6) appeared to be least strongly correlated with one's decision to adopt a new technology. While Tornatzky and Klein (1982) found that a similar construct to an innovation's ease of use, complexity, was another key attribute that determined one's decision to adopt, further research by Davis (1989) showed that it was not as influential in one's decision. My research shows that, in accordance with Davis, one's perception of how easy it is to use a new technology is correlated, but not as strongly, with one's decision to adopt. While Davis explained that a certain degree of complexity is important for some innovations, I would have expected that, for certain "smart" technologies aimed at facilitating one's daily life, ease of use would have been more highly correlated with adoption than it might be for other innovations that lack digital components. Even so, if a technology is perceived as easy to use, it might be more likely to be considered for purchase.

One's perceived ability to try a new technology before purchasing (trialability; H4), while significantly correlated, was also not as strongly related (compared to other attributes) to one's intention to purchase a new technology. Even so, if individuals feel 
that they have opportunities for hands-on learning about an innovation, they will be more likely to consider adopting that technology. In the diffusion of innovations model, Rogers explains how trialability lowers one's uncertainty about an innovation and, perhaps, better understand how it might fit into their lives (Rogers, 2003). It is possible that one's perception of trialability is not as strongly correlated with one's interest in adopting because of one's access to alternative sources of information, like written reviews and online video reviews, about a new technology. It is also necessary to consider the fluctuating importance of each attribute, including trialability, depending on the specific technology product being evaluated. A technology product that can be assessed based on, for example, software components or color (i.e. a laptop or a bookshelf), might not have as strong of an impact on one's necessity to try before purchasing, whereas a product based on tactile or aural qualities might have a greater need for trialability (i.e. the feel of a mattress, the sound of a washing machine). Additionally, there are likely subsets of the consumer population that prefer to evaluate items in-store regardless of a product's other attributes, thus increasing those individuals' perceptions of trialability importance. One's perception of how visible (H3) an innovation is, similarly to other attributes, correlated with one's interest in purchasing a new technology. If individuals felt that an innovation was observable in their daily life, or when they sought it out, they would be more likely to purchase it in the future. While not all technologies are observable, individuals often make judgements about those that are. Since "smart" refrigerators include both hardware (the tangible device) and software (the programs that give functionality to the device) components, it is possible that individuals are more inclined to purchase a "smart" refrigerator because of one's likelihood of seeing it in daily 
life, compared with software-only technologies. Seeing an unfamiliar new technology would likely create uncertainty, which could lead to information seeking and knowledge gain (Rogers, 2003). If the communication about a new technology's attributes are perceived positively, it is understandable that an individual would be inclined to purchase it.

Since individuals are most likely to see "smart" refrigerators in the homes of friends or acquaintances, it is important to think about how individuals interact and communicate about new technologies. Interpersonal communication is one of the main channels by which individuals hear about, and are persuaded to adopt, new technologies. One's social system defines the structure of how these ideas are spread throughout a population and, when one's acquaintances and friends encourage technology adoption, one is more likely to do so. In general, "an individual is more likely to adopt an innovation if more of the other individuals in his or her personal network have adopted previously" and that "earlier adopters have greater knowledge of innovations than do later adopters" (Rogers, 2003, p. 291, 359; Valente, 1995). As with other channels, interpersonal communication is often dependent upon the trust and influence that individuals have upon each other (Rogers, 2003). Cialdini, Reno, and Kallgren note how there could be situations in which norms play roles but that, in general, norms only "motivate behavior when they are activated" (Cialdini, Reno, \& Kallgren, 1990, p. 1015). Specifically, when considering whether or not to use a smart refrigerator, it appears that descriptive norms are slightly more salient than subjective norms. In other words, one's opinion about if others were using smart refrigerators was more influential in their interest to use one, rather than whether or not one thought that they should be using one 
according to their friends. This follows the predictions of the theory of normative social behavior (Rimal \& Real, 2003). A multiple linear regression showed that descriptive norms play a major role in one's perception of technology and decision to purchase. My research emphasizes how frequently individuals receive technology-related advice from others and how influential this communication might be in one's future decisions. Given the importance of descriptive norms in one's decision to use smart refrigerators, in addition to the emphasis placed on social influence for technology diffusion in general, it is important that future operationalizations of technology acceptance models focusing on "smart" technologies incorporate constructs that measure descriptive norms.

Another novel finding in my research showed that individuals felt greater interest in using a new technology if they felt that it had greater customizability (H7). Past research has shown that greater innovation re-invention often leads to greater adoption rates, but little to no research has specifically looked at how the customizability of a digital, "smart," technology affects its rate of adoption (Rogers, 2003). In running a multiple linear regression, I found that customizability is one of three significant predictors (among relative advantage/ perceived usefulness and descriptive norms) that significantly influences one's decision to purchase new technology. In recent years with the increase of digital technology, retail technologies have found niches developing customizable keyboards, game controllers, and wi-fi-controlled lights, among others (McQuarrie, 2015). My research provides the basis for adding "customizability" as one of the key attributes for the adoption of new, digital technologies. Future operationalizations of technology acceptance models for "smart" technology should incorporate the construct of "customizability." 
Contrary to how a technology that has the option of being customizable seems to correlate with individuals' interest in purchasing a new technology, individuals' concerns about a technology's security (H8) did not seem to have an effect on one's decision to adopt an innovation. With the growth of internet-connected technologies and increasing "worries over digital dystopia," one would think that privacy concerns would be of utmost importance when considering adopting new technologies (Anderson \& Rainie, 2018). Despite this, more recent research by Smith (2018) has shown that $74 \%$ of all adults and $83 \%$ of college students think that major technology companies do "more good than bad" in terms of the impact on one's personal life (Smith, 2018). Additionally, it is estimated that $95 \%$ of cybersecurity breaches are due to human error (Cybint News, 2018). Assuming that people think highly of technology companies or their own abilities to navigate security issues, perhaps individuals directly associate their opinion about digital technologies with the companies that create them, or the faith they have in their own ability to navigate a new device. This might explain why privacy concerns might not be as integral of a component in one's decision to adopt compared to the benefits that individuals see within an innovation.

The post-hoc correlations of one's intention to use a smart refrigerator if cost is not a factor in one's decision differed from my hypotheses tests in terms of elucidating which factors individuals find relevant for technology adoption. When cost is not a factor, a technology's relative advantage/ usefulness, compatibility, ease of use, customizability, and concerns about the privacy and security of the technology are statistically significantly correlated with one's intent to use. Since the individual would not have spent time choosing this technology, relative advantage/ usefulness and 
compatibility would be important in one's decision to keep the technology since, most likely, they did not see its necessity in the first place (or else they would have purchased it). Since cost is not a factor in one's choice, one of the only downsides of accepting a free product might be the time it takes to learn how to use it, thus supporting how ease of use correlates with one's decision to use. Additionally, privacy concerns were negatively correlated with one's decision to use a free "smart" technology. Perhaps these concerns would be considered more of a factor because an individual might question the security of a free "smart" technology product, opposed to one that had been purchased; the latter would likely be sold from a retailer that values the vetting of products and product security, compared to the organizers of a giveaway raffle. On the other hand, social influence, visibility, and trialability are not significantly correlated with one's intention to use a "smart" technology product if cost is not an issue. Often, free products come with "low expectations" and "neutral perceptions" which might undermine the need to receive social feedback, see the product in action, or try before using (n.d., Powers, para. 6).

\section{Limitations and Future Research}

Despite my best efforts, there are limitations to any research study. Participants included only undergraduate students in the Communication Department at a public, Northwestern, university. This particular population might have more progressive views about technology adoption that are not held by all technology's target markets. Participant lack of survey engagement and misinterpretation of questions could skew responses. While there are advantages and disadvantages to surveying a specific population, future research might expand the range of participants outside of the university environment to better understand how others form opinions about new, digital technologies. Focusing on 
groups that are considered target markets for a particular product might elucidate more relevant attributes for those populations. Future research should seek to include a larger number of participants in survey research as well to increase the power of statistical tests discussed in this study.

Another limitation to this study is my survey's focus on measuring participant opinion using "smart refrigerators" as the representative technology. Theoretical models emphasize the importance of evaluating technologies that individuals are aware of, but have not yet adopted, and "smart refrigerators" represent only one of the current innovations that fulfill this objective. Using other devices that fulfill this objective might uncover additional attributes that individuals perceive as relevant to their adoption decisions.

Before participants answered questions about their opinion of "smart refrigerators," a short paragraph was presented to familiarize them with this technology. The paragraph that was used was promotional material for a smart refrigerator that is currently available (Meet LG ThinQ, 2018). It could be worth considering if there is a difference in responses based on the tone and content of this paragraph. Future research might compare opinions about perceived attributes seen in new technology depending on whether participants receive a promotional versus a technical explanation of a "smart" refrigerator's features.

The scales of "specific technology knowledge," "general technology knowledge," (Hosseini and Kamal, 2012) and "customizability" (Guilabert \& Donthu, 2003) are worth evaluating more in depth. The scale that measured "specific technology knowledge" showed no correlation with one's intention to purchase a specific technology. The 
similarity between this scale and those representing "self-efficacy" are similar, thus suggesting that the construct being measured is different than what was intended (Schwarzer \& Jerusalem, 2013). In a meta-analysis by Tornatzky and Klein (1982), the authors found "thirty different characteristics" that had been incorporated into past technology adoption studies, "[raising] serious questions about the independence of ... dimensions" used in this type of research (p. 33). For example, within the current research, the questions within the "general technology knowledge" scale seem to, potentially, be asking about one's experience with technology, rather than their knowledge about technology. Additionally, the "customizability" scale is not consistently specific regarding a smart refrigerator: Some questions imply that the device would be customized before a customer receives it, which is different than what was intended, in this study, by device "customizability," since the latter assumes a product can be altered by the consumer. Future studies could ask only one item about participant opinion of the specific customizable device in question, or could tailor customizability questions to a specific device (i.e. "If I could customize a smart refrigerator to set timers and provide recipes based on the contents of my fridge, I would be more likely to purchase it, compared to a standard [non-internet-connected] refrigerator."). Perhaps better wording of questions in these three scales could have clarified the original conceptualization of "specific technology knowledge," "general technology knowledge," and "customizability."

My research focused on evaluating the attributes within the diffusion of innovations model and technology acceptance models for, specifically, devices that can connect to the internet. Future research should evaluate the current scales for usefulness 
and relative advantage to further explore how these can be measured as separate constructs. Current and past research has shown that usefulness has a significant effect on one's intention to adopt (Davis, 1989). Despite this, it is worth evaluating the relationship that one's opinion about a technology's perceived usefulness might have on one's inclination to search for information (increasing one's knowledge about a specific technology) which, in turn, would affect one's intention to adopt (Widavsky \& Dake, 1990; Miller, 2004). Venkatesh, Morris, Davis, and Davis (2003) found that ease of use, as included in early technology adoption models, was not as important in determining one's intention to adopt. In my research, I found that it was still important. Perhaps evaluating ease of use with technologies that can connect to the internet elicit different opinions about attributes compared to technologies that cannot. Future research should focus on evaluating various internet-connected devices (and non-internet devices) to evaluate how the type of technology effects attribute importance.

Future research could determine why privacy concerns are not as significant in one's decision to purchase innovations, even when individuals are aware of potential security hazards. Individuals appeared to not be too worried about privacy concerns in relation to smart refrigerators, but perhaps other "smart" technologies would elicit varying degrees of security concerns. On the contrary, privacy concerns were significant in one's decision to use if a "smart" technology was given away for free. Does having greater interest in a product decrease one's interest in evaluating cybersecurity issues? If "roughly half of Americans think their personal data are less secure (now) compared with five years ago" (Smith, 2017, para. 11), this could lead to apathy when deciding to adopt new technologies. It would be interesting to evaluate how privacy and security concerns 
change over time as cybercrime stories regarding new, digital, technology fluctuate in the media.

\section{Conclusions}

Research about new, digital, technologies is growing rapidly. With the ubiquitous introduction of devices that can connect to the internet, future research should continue to evaluate attributes that influence technology adoption. The diffusion of innovations model, technology acceptance models, and social network theory appear to provide a substantial basis for understanding how technology is adopted. It could be beneficial to further test and use my set of combined scales (which incorporate constructs from each of these models) to better predict technology acceptance for upcoming "smart" devices.

One of the most influential aspects of my research is that customizability and social influence (specifically, descriptive norms) appear to be highly correlated with one's intention to use a new, "smart" technology, whether an individual intends to purchase it or has won it. Future studies should extend extant technology acceptance models and add customizability and social influence (specifically, descriptive norms) as attributes for considering "smart" technology adoption. Operationalizations of technology acceptance models and diffusion of innovations models that are attempting to gauge acceptance of a "smart" technology should be sure to include scales for customizability and descriptive norms. These two attributes account for a significant amount of variance and should not be ignored.

This study builds upon the diffusion of innovations model and extends technology acceptance models to include the construct of customizability for internet-connected devices. In examining participant opinion toward new technologies, I found that one's 
perception of a technology's relative advantage, compatibility with one's lifestyle, perceived usefulness, perceived ease of use, visibility, and trialability, are all primarily components of one's decision-making process. I found that it is worth considering the role that one's social interactions play in this process and, for devices that connect to the internet, it is important to consider one's concerns surrounding privacy and security. The current research has contributed to expanding the framework for technology adoption criteria that can be used within marketing strategy for internet-connected devices. By understanding how frequently individuals receive technology advice from others, marketing strategists might shift toward or continue using influencers more frequently in order to reach certain target markets; additional attributes, like customizability, should be considered (in addition to those in extant technology acceptance models) while conducting market research and developing marketing strategies. While future research is necessary to achieve a more specific understanding of technology marketing for various types of innovations, my research can improve the design process for future devices and will influence the objectives of current technology marketing efforts. 


\section{References}

Ajzen, I. (2013). Theory of planned behavior questionnaire. Measurement Instrument Database for the Social Science. Retrieved from www.midss.ie

Anderson, J., \& Rainie, L. (2018, April 17). The future of well-being in a tech-saturated world. Pew Research Center, Washington, D. C. Retrieved from https://www.pewinternet.org/2018/04/17/the-future-of-well-being-in-a-techsaturated-world/

Anderson, M. (2015, October 29). Technology device ownership: 2015. Pew Research Center, Washington, D. C. Retrieved from http://www.pewinternet.org/2015/10/29/technology-device-ownership-2015/

AWS DeepLens. (2018). Retrieved from https://aws.amazon.com/deeplens/

Baaren, E., van de Wijngaert, L., \& Huizer, E. (2011). Understanding technology adoption through individual and context characteristics: The case of HDTV. Journal of Broadcasting \& Electronic Media, 55(1), 72-89. doi: $10.1080 / 08838151.2011 .546257$

Blecker, T., Friedrich, G., Kaluza, B., Abdelkafi, N., \& Kreutler, G. (2005). Customization. In Information and management systems for product customization. Springer.

boyd, d. (2017, October 4). Your data is being manipulated [web log post]. Retrieved from https://points.datasociety.net/your-data-is-being-manipulated-a7e31a83577b

Burt, R. S. (1999). The social capital of opinion leaders. Annals of the American Academy of Political and Social Science, 566(1), 37-54. doi: $10.1177 / 0002716299566001004$ 
Carroll, J., \& Thomas, J. (1988). Fun. SIGCHI Bulletin, 19(3).

doi: $10.1145 / 49108.1045604$

CES. (2018). Retrieved from https://www.ces.tech

Chung, A., \& Rimal, R. N. (2016). Social norms: A review. Review of Communication Research, 4(1), 1-28. doi:10.12840/issn.2255-4165.2016.04.01.008

Cialdini, R., Reno, R. \& Kallgren, C. (1990). A focus theory of normative conduct: Recycling the concept of norms to reduce littering in public places. Journal of Personality and Social Psychology, 58(6), 1015-1026.

Clarke, M. (2014, January 17). Fridge sends spam emails as attach hits smart gadgets. BBC News. Retrieved from https://www.bbc.com/news/technology-25780908

Cronbach, L. (1951). Coefficient alpha and the internal structure of tests. Psychometrika. $16(3), 297-334$.

Cybint News (2018, December 3). 13 alarming cyber security facts and stats [web log post]. Retrieved from https://www.cybintsolutions.com/cyber-security-facts-stats/

Dadayan, L., \& Ferro, E. (2005). When technology meets the mind: A comparative study of the technology acceptance model. In M. A. Wimmer, R. Traunmüller, Å. Grönlund, \& K. V. Andersen (Eds.), Electronic Government. 3591, 137-144. doi:10.1007/11545156_13

Davis, F. D. (1989). Perceived usefulness, perceived ease of use, and user acceptance of information technology. MIS Quarterly, 13(3), 319. doi:10.2307/249008

Evans, G., \& Durant, J. (1995). The relationship between knowledge and attitudes in the public understanding of science in Britain. Public Understanding of Science, 4(1), 57-74. doi:10.1088/0963-6625/4/1/004 
Guilabert, M. B., \& Donthu, N. (2003). Mass customization and consumer behavior: The development of a scale to measure customer customization sensitivity, 1-12.

Heinz, M. S. (2013). Exploring predictors of technology adoption among older adults, 1115.

Hung, M. (2017). Gartner insights on how to lead in a connected world. Retrieved from https://www.gartner.com/imagesrv/books/iot/iotEbook_digital.pdf

iPhone. (2018). Retrieved from https://www.apple.com/iphone/

Jay, G., \& Willis, S. (1992). Influence of direct computer experience on older adults' attitudes toward computers. Journal of Gerontology, 47(4), P250-P257.

Jiang, H. (2010). Young people's adoption and consumption of a cultural commodityiPhone (Master's thesis). London School of Economics and Political Science, London, UK.

Joo, J., \& Sang, Y. (2013). Exploring Koreans' smartphone usage: An integrated model of the technology acceptance model and uses and gratifications theory. Computers in Human Behavior, 29(6), 2512-2518. doi:10.1016/j.chb.2013.06.002

Kikuchi, M., \& Coleman, C.-L. (2012). Explicating and measuring social relationships in social capital research. Communication Theory (1050-3293), 22(2), 187-203. doi:10.1111/j.1468-2885.2012.01401.x

Lin, C.-H., Shih, H.-Y., \& Sher, P. J. (2007). Integrating technology readiness into technology acceptance: The TRAM model. Psychology and Marketing, 24(7), 641-657. doi:10.1002/mar.20177

Liu, W., Sidhu, A., Beacom, A. M., \& Valente, T. W. (2017). Social network theory. In P. Rössler, C. A. Hoffner, \& L. van Zoonen (Eds.), The International 
Encyclopedia of Media Effects, 1-12. Hoboken, NJ, USA: John Wiley \& Sons, Inc. doi:10.1002/9781118783764.wbieme0092

Manata, B. (2019). The structural effects of team density and normative standards on team member performance. Human Communication Research. 00: 1-25. doi:10.1093/hcr/hqz003

Mazaika, K. (2017, January 20). Will the demand for developers continue to increase? Forbes. Retrieved from https://www.forbes.com/sites/quora/2017/01/20/will-thedemand-for-developers-continue-to-increase/\#652585a733ee

McKnight, D. H., Lankton, N., \& Tripp, J. (2010). Social networking information disclosure and continuance intention: A disconnect. 2011 44th Hawaii International Conference on System Sciences, 1-10. doi:10.1109/HICSS.2011.379

McQuarrie, L. (2015, December 15). 22 customizable technology products. [web log post]. Retrieved from https://www.trendhunter.com/slideshow/customization-andtechnology

Meet LG ThinQ. (2018). Retrieved from https://www.lg.com/us/lg-thinqappliances/products/lg-instaview-thinq/index

Miller, J. D. (2004). Public understanding of, and attitudes toward, scientific research: What we know and what we need to know. Public Understanding of Science, 13(3), 273-294. doi:10.1177/0963662504044908

Moore, G. C., \& Benbasat, I. (1991). Development of an instrument to measure the perceptions of adopting an information technology innovation. Information Systems Research, 2(3): 192-220. doi:10.1287/isre.2.3.192 
Parasuraman, A. (2000). Technology readiness index (Tri): A multiple-item scale to measure readiness to embrace new technologies. Journal of Service Research, 2(4), 307-320. doi:10.1177/109467050024001

Parasuraman, A., \& Colby, C. L. (2015). An updated and streamlined technology readiness Index: TRI 2.0. Journal of Service Research, 18(1), 59-74. doi: $10.1177 / 1094670514539730$

Park, H. S., \& Smith, S. W. (2007). Distinctiveness and influence of subjective norms, personal descriptive and injunctive norms, and societal descriptive and injunctive norms on behavioral intent: A case of two behaviors critical to organ donation. Human Communication Research, 33(2), 194-218. doi:10.1111/j.14682958.2007.00296.x

PC Mag Staff. (2017, January 6). The Best of CES 2017. PC Mag. Retrieved from https://www.pcmag.com/news/350860/the-best-of-ces-2017

Powers, M. (n.d.) Why are people attracted to giveaways: The science of free [web log post]. Retrieved from https://www.bluesodapromo.com/blog/why-are-peopleattracted-to-giveaways-the-science-of-free/

Nisbet, M., Scheufele, D., Shanahan, J., Moy, P., Brossard, D., \& Lewenstein, B. (2002). Knowledge, reservations, or promise? Communication Research, 29(5), 584-608.

Rae, H. (2019, January 1). Best robotic vacuums of 2019 [web log post]. Consumer Reports. Retrieved from https://www.consumerreports.org/robotic-vacuums/bestrobotic-vacuums-of-the-year/

Rainie, L. (2017, September 13). About 6 in 10 young adults in U.S. primarily use online streaming to watch TV. Pew Research Center, Washington, D. C. Retrieved from 
http://www.pewresearch.org/fact-tank/2017/09/13/about-6-in-10-young-adults-inu-s-primarily-use-online-streaming-to-watch-tv/

Rice, R. E. (2009). Diffusion of innovations: theoretical extensions. In R. L. Nabi \& M. B. Oliver (Eds.), The Sage Handbook of Media Processes and Effects (489-501). New York: SAGE Publications, Inc.

Rimal, R. N., \& Real, K. (2005). How behaviors are influenced by perceived norms: A test of the theory of normative social behavior. Communication Research, 32(3), 389-414. doi:10.1177/0093650205275385

Rimal, R. N., \& Lapinski, M. K. (2015). A re-explication of social norms, ten years later: Social norms. Communication Theory, 25(4), 393-409. doi:10.1111/comt.12080

Rojas, H., Barnidge, M. (2017). Social capital. doi:10.1093/OBO/9780199756841-0115. Retrieved from http://www.oxfordbibliographies.com.proxy.lib.pdx.edu/view/document/obo9780199756841/obo-9780199756841-0115.xml?rskey=UIdiEN\&result=181

Rogers, E. M. (2003). Diffusion of innovations (3rd ed). New York, NY: Free Press. Samsung. (2018). Retrieved from https://www.samsung.com/us/mobile/phones/

Sensoria. (2018). Retrieved from http://www.sensoriafitness.com

Schwarzer, R. \& Jerusalem, M. (2013). General self-efficacy scale (GSE). Measurement Instrument Database for the Social Science. Retrieved from www.midss.ie Skymind. (2018). Retrieved from https://skymind.ai/wiki/ai-vs-machine-learning-vsdeep-learning 
Smith, A. \& Anderson, M. (2017, October 4). Automation in everyday life. Pew Research Center, Washington, D. C. Retrieved from http://www.pewinternet.org/2017/10/04/automation-in-everyday-life/

Smith, A. (2014, November 25). What internet users know about technology and the web. Pew Research Center, Washington, D. C. Retrieved from http://www.pewinternet.org/2014/11/25/about-the-survey-4/

Smith, A. (2017) Americans and cybersecurity. Pew Research Center, Washington, D. C. Retrieved from https://www.pewinternet.org/2017/01/26/americans-andcybersecurity/

Smith, A. (2018). Public attitudes toward technology companies. Pew Research Center, Washington, D. C. Retrieved from https://www.pewinternet.org/2018/06/28/public-attitudes-toward-technologycompanies/

Song, V. (2017, January 5). Misfit Vapor. PC Mag. Retrieved from https:/www.pcmag.com/review/350819/misfit-vapor

Sperry, Todd. (2012, October 10). Car colors: white to blend in, green for rebels. CNN. Retrieved from https://www.cnn.com/2012/10/10/us/car-colors/index.html St. John, Allen. (2018, March 8). Tech gadgets and older adults: what helps, what doesn't [web log post]. Consumer Reports. Retrieved from https://www.consumerreports.org/electronics/tech-gadgets-and-older-adults-whathelps-what-doesnt/

Tesla. (2018). Retrieved from https://www.tesla.com 
Tornatzky, L. G., \& Klein, K. J. (1982). Innovation characteristics and innovation adoption-implementation: A meta-analysis of findings. IEEE Transactions on Engineering Management, EM-29(1), 28-45. doi:10.1109/TEM.1982.6447463

University of Michigan. Survey Research Center. Economic Behavior Program. Survey of Consumer Attitudes and Behavior. ICPSR35365. Ann Arbor, MI: Interuniversity Consortium for Political and Social Research. 2004. doi:10.3886/ICPSR35365.v1

Vannoy, S. A., \& Palvia, P. (2010). The social influence model of technology adoption. Communications of the ACM, 53(6), 149. doi:10.1145/1743546.1743585

Valente, T. W., Watkins, S. Jato, M. N., Van der Straten, A., and Tsitsol, L. M. (1997). Social network associations with contraceptive use among Cameroonian women in voluntary associations. Social Science and Medicine, 45, 677-687.

Valente, T. W. (2008). Social Networks. In W. Donsbach (Ed.), The International Encyclopedia of Communication. Chichester, UK: John Wiley \& Sons, Ltd. doi:10.1002/9781405186407.wbiecs065

Venkatesh, Morris, Davis, \& Davis. (2003). User acceptance of information technology: Toward a unified view. MIS Quarterly, 27(3), 425. doi:10.2307/30036540

Wildavsky, A., \& Dake, K. (1990). Theories of risk perception - who fears what and why. Daedalus, 119(4), 41-60.

World Economic Forum (2017). Global risks of highest concern. Retrieved from http://reports.weforum.org/global-risks-2018/global-risks-of-highest-concern-fordoing-business-2018/\#country/USA 
Appendix A: Survey Instrument

\section{Thesis Survey: Technology Adoption}

\section{Start of Block: Informed Consent}

\section{Informed Consent Form}

You are invited to participate in a research study conducted by Laura Glass under the direction of Dr. Frank. This study attempts to collect information about your opinions on new technologies. You were selected as a possible participant in this study because you are enrolled as an undergraduate in a communication course.

\section{Procedures}

If you decide to participate, you will be asked to complete the following questionnaire. The questionnaire will take approximately 20 minutes or less.

\section{Risks/Discomforts}

Risks are minimal for involvement in this study. You are welcome to skip any questions that you feel uncomfortable answering.

\section{Benefits}

You may not receive any direct benefit from taking part in this study. However, it is hoped that through your participation, the study may help to increase knowledge which may help others in the future.

\section{Confidentiality}

All information that is obtained in connection with this study will be kept confidential and will only be reported in an aggregate format (by reporting only combined results and never reporting individual ones). All questionnaires will be concealed, and no one other than the research team will have access to them. At no point will your name be linked to your answers.

\section{Compensation}

You may earn academic extra credit for your participation. Follow the directions at the end of the survey to print and turn your survey completion form in to the pink drop box in the Communication Department offices, UCB 440. Your form will not be linked to your survey responses. Your name is collected only so that your professor may give you extra credit for your class project.

\section{Participation}

Participation in this research study is completely voluntary. You have the right to withdraw at any time or refuse to participate entirely, and it will not affect your course 
grade in the class or standing with the university. If you wish to receive extra credit but do not wish to complete the survey, contact the researcher for an alternative extra credit opportunity.

\section{Questions about the Research}

If you have questions or concerns regarding this study, contact Laura Glass at lglass@pdx.edu or Dr. Frank at1frank@pdx.edu.

\section{Questions about your Rights as Research Participants}

If you have questions or concerns about your rights as a research subject, please contact the PSU Office of Research Integrity, Market Center Building 6th floor, Portland State University, 503-725-5484.

By completing this survey, you are certifying that you are 18 years of age or older, that you have read and understand the above information and agree to take part in the survey. Press the "Print" button below to keep a copy of this form for your own records.

If, at this point, you choose to continue in this research study, please click ">>" to continue. 


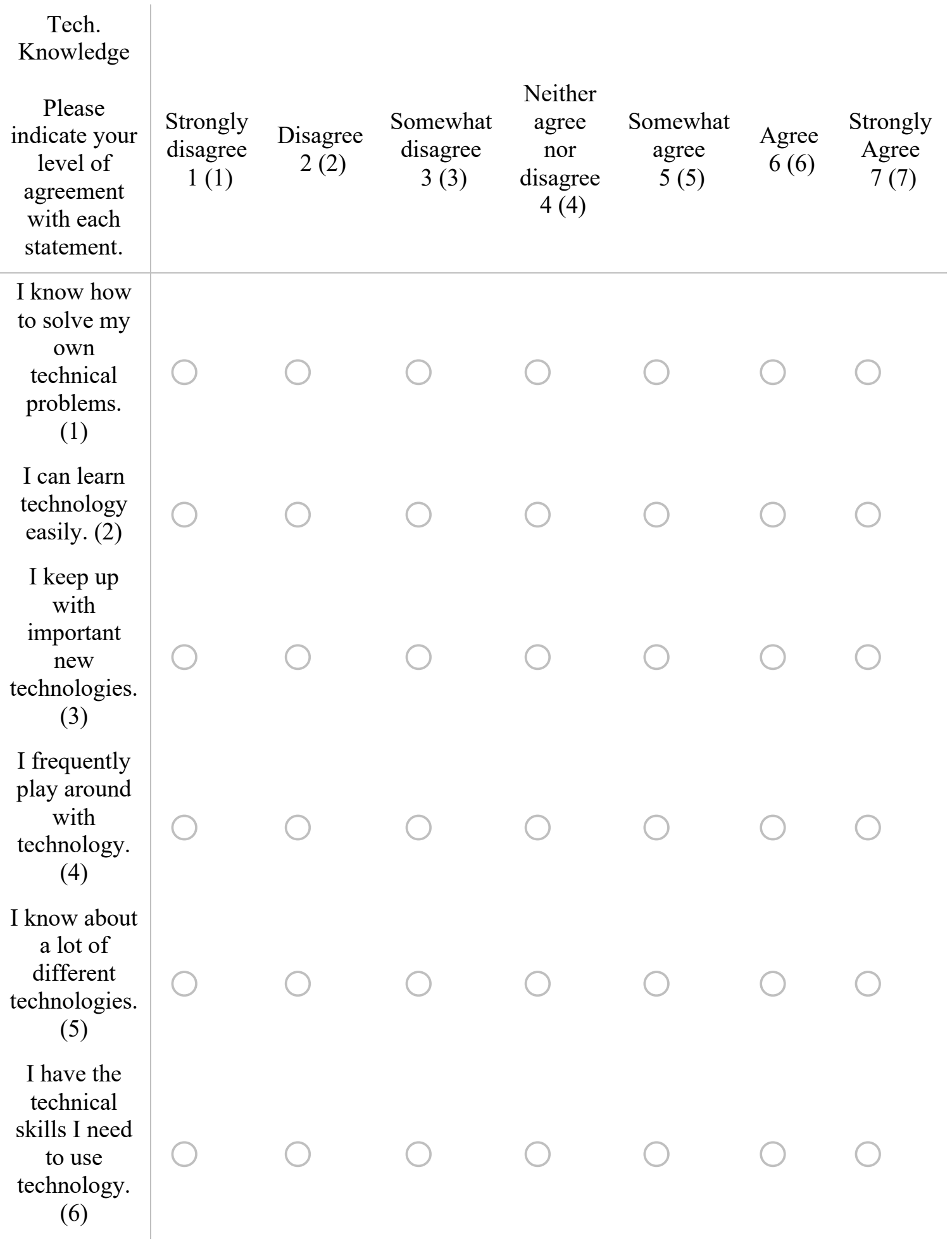




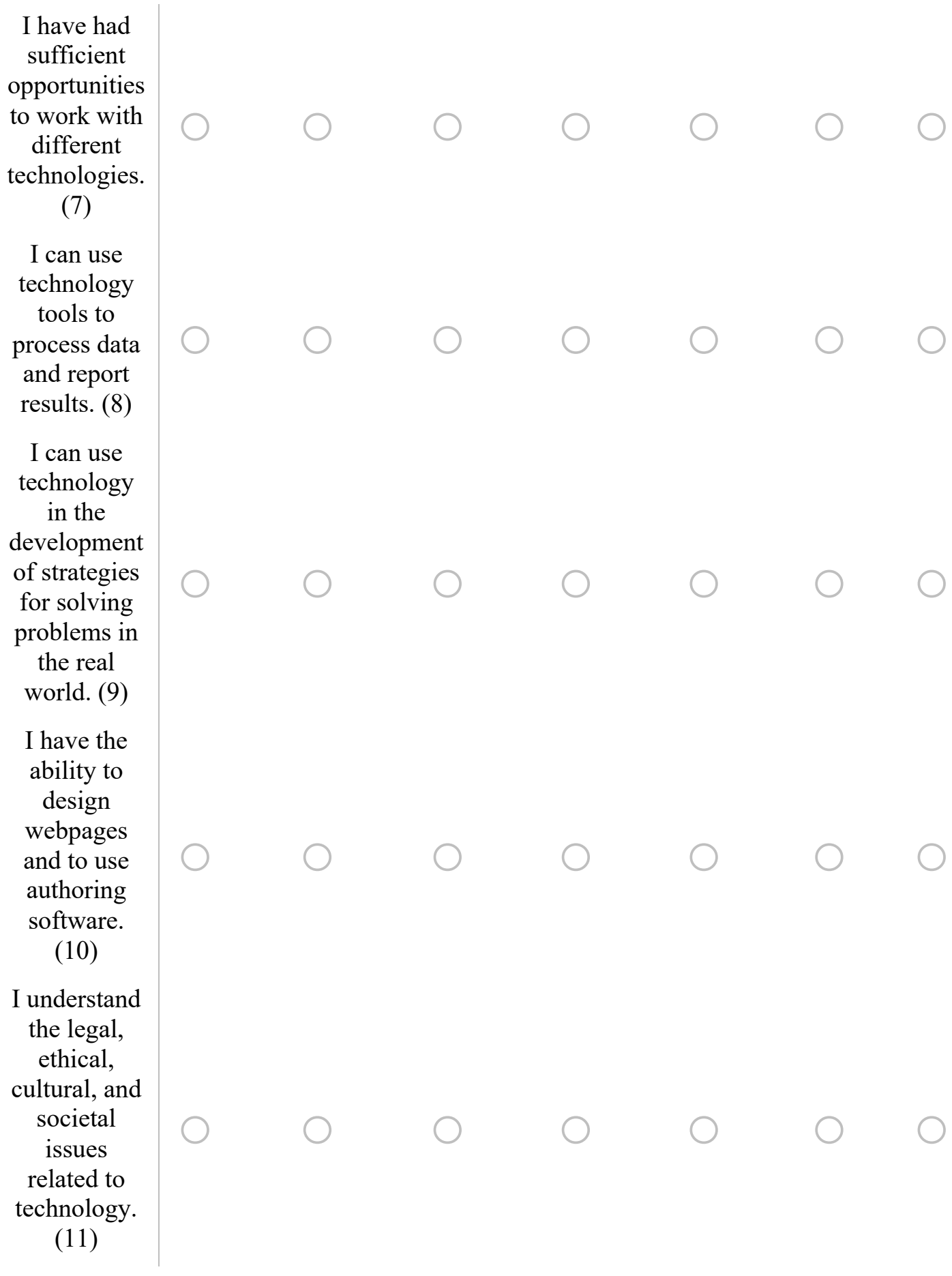


Awareness

Have you heard of a "smart" refrigerator?

Yes (1)

No (2)

End of Block: Technology Knowledge/ Have you heard of a smart refrigerator

Start of Block: Smart Refrigerator description (LG ThinQ)

Timing Timing

First Click (1)

Last Click (2)

Page Submit (3)

Click Count (4)

\section{SR Description}

You will be asked questions about the following paragraph. Please read it carefully.

Want a refrigerator that will recommend recipes, create shopping lists and play music for your meal? A "smart" refrigerator can. Experience a refrigerator which lets you create and share shopping lists between your smartphone and refrigerator, or check on the contents of your refrigerator, anytime, anywhere. Internal cameras give you real-time updates of what's in the refrigerator. Get step-by-step instructions to make your favorite recipes. Get an alert when groceries are about to expire and order more right from your refrigerator. Enjoy peace of mind with a refrigerator that knows how to optimize settings so that it can be even more energy efficient.

\section{End of Block: Smart Refrigerator description (LG ThinQ)}


Tech Content Knowldg Please indicate your level of agreement with each statement.

\begin{tabular}{|c|c|c|c|c|c|c|}
\hline $\begin{array}{c}\text { Strongly } \\
\text { disagree } \\
1 \text { (1) }\end{array}$ & $\begin{array}{c}\text { Disagree } \\
2(2)\end{array}$ & $\begin{array}{c}\text { Somewhat } \\
\text { disagree } \\
3(3)\end{array}$ & $\begin{array}{l}\text { Neither } \\
\text { agree } \\
\text { nor } \\
\text { disagree }\end{array}$ & $\begin{array}{c}\text { Somewhat } \\
\text { agree } \\
5(5)\end{array}$ & $\begin{array}{c}\text { Agree } \\
6(6)\end{array}$ & $\begin{array}{c}\text { Strongly } \\
\text { agree } \\
7(7)\end{array}$ \\
\hline
\end{tabular}

I know about technologies that I could use for understanding how smart refrigerators work. (1)

I could learn how to use specific software related to smart refrigerators. (2)

I can find and evaluate the resources that I need in order to better understand smart refrigerators. (3) 
EoU Please respond to the following questions regarding your perceived ability to use a smart refrigerator.

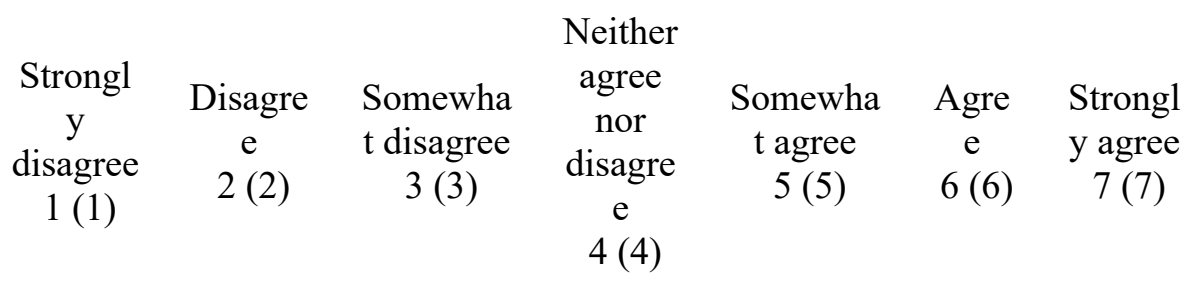

\footnotetext{
Learning to operate a smart refrigerator would be easy for me. (1)

I would find it easy to get a smart refrigerator to do what I want it to do. (2)

My interaction with a smart refrigerator would be clear and understandable . (3)

I would find a smart refrigerator to be flexible to interact with.

It would be easy for me to become skillful at using a smart refrigerator. (5)

I would find a smart refrigerator easy to use. (6)
} 
End of Block: Technology content knowledge/ Tech. Attributes: Ease of Use

Start of Block: Interest Level in Adopting a New Technology 


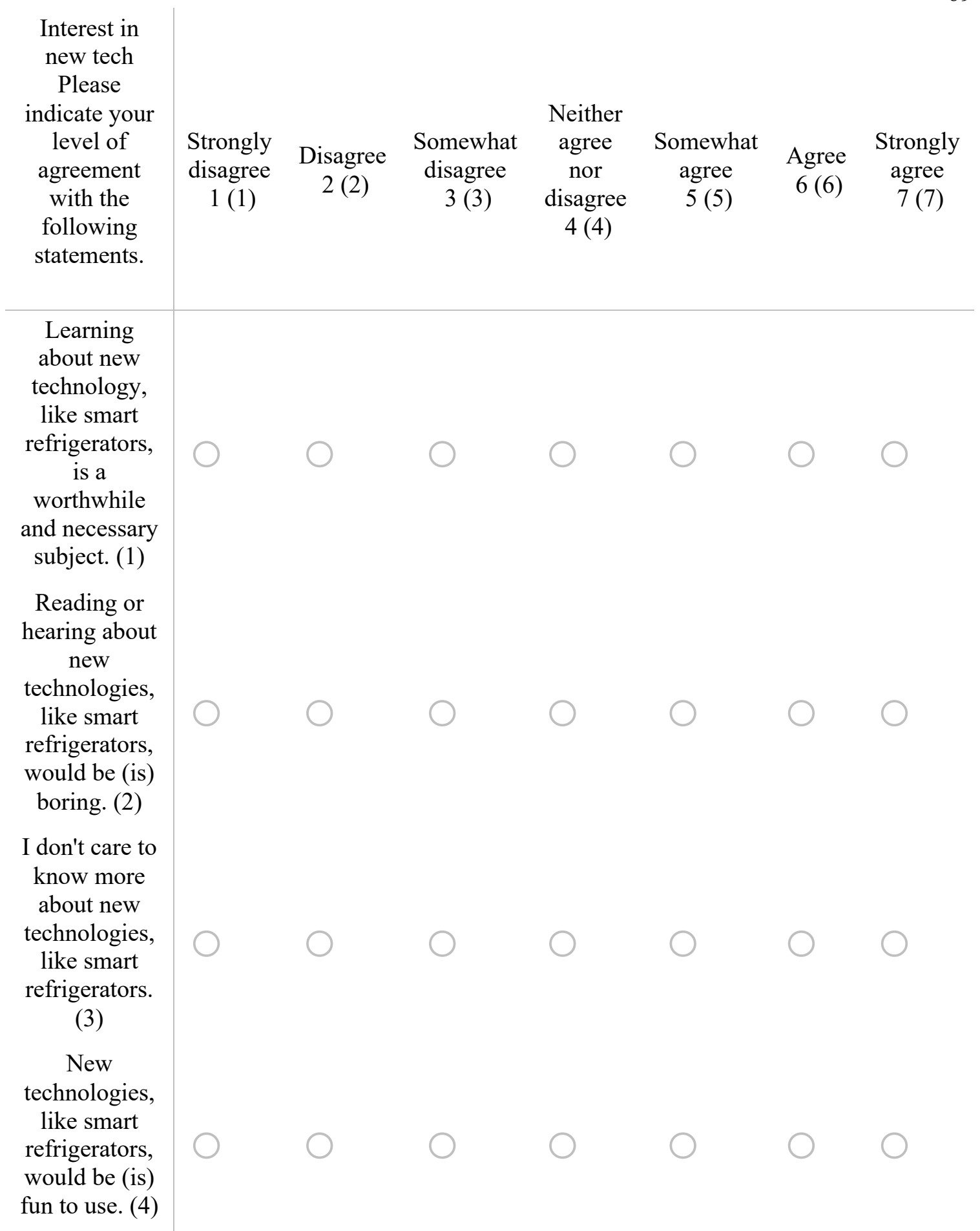




\begin{abstract}
Learning about new technologies, like smart refrigerators, is a waste of time. (5)

If cost were not an issue, I would consider purchasing a smart refrigerator.
\end{abstract}




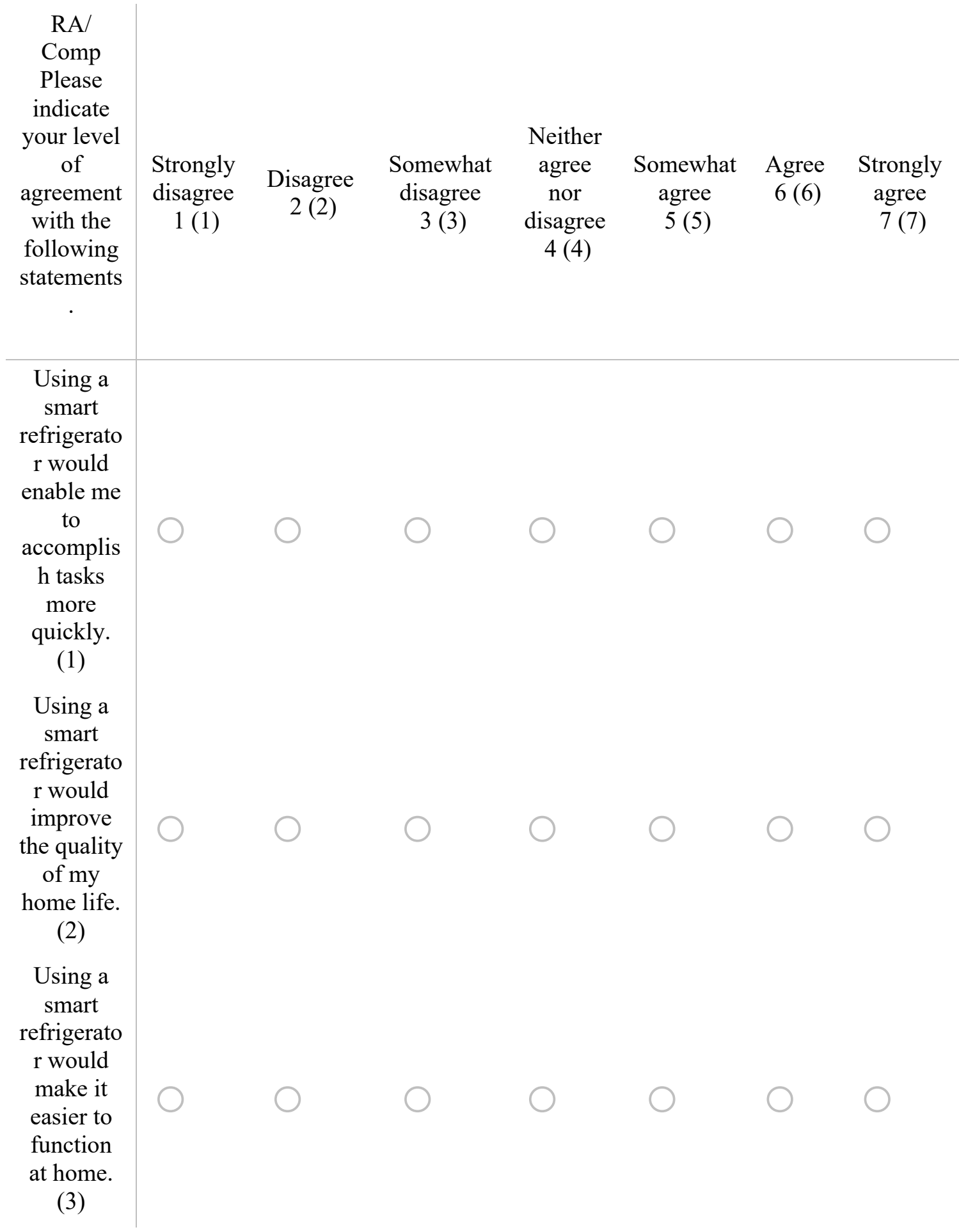




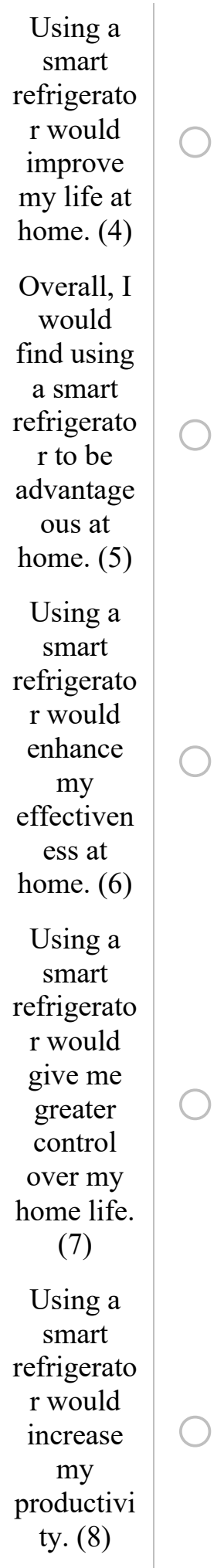




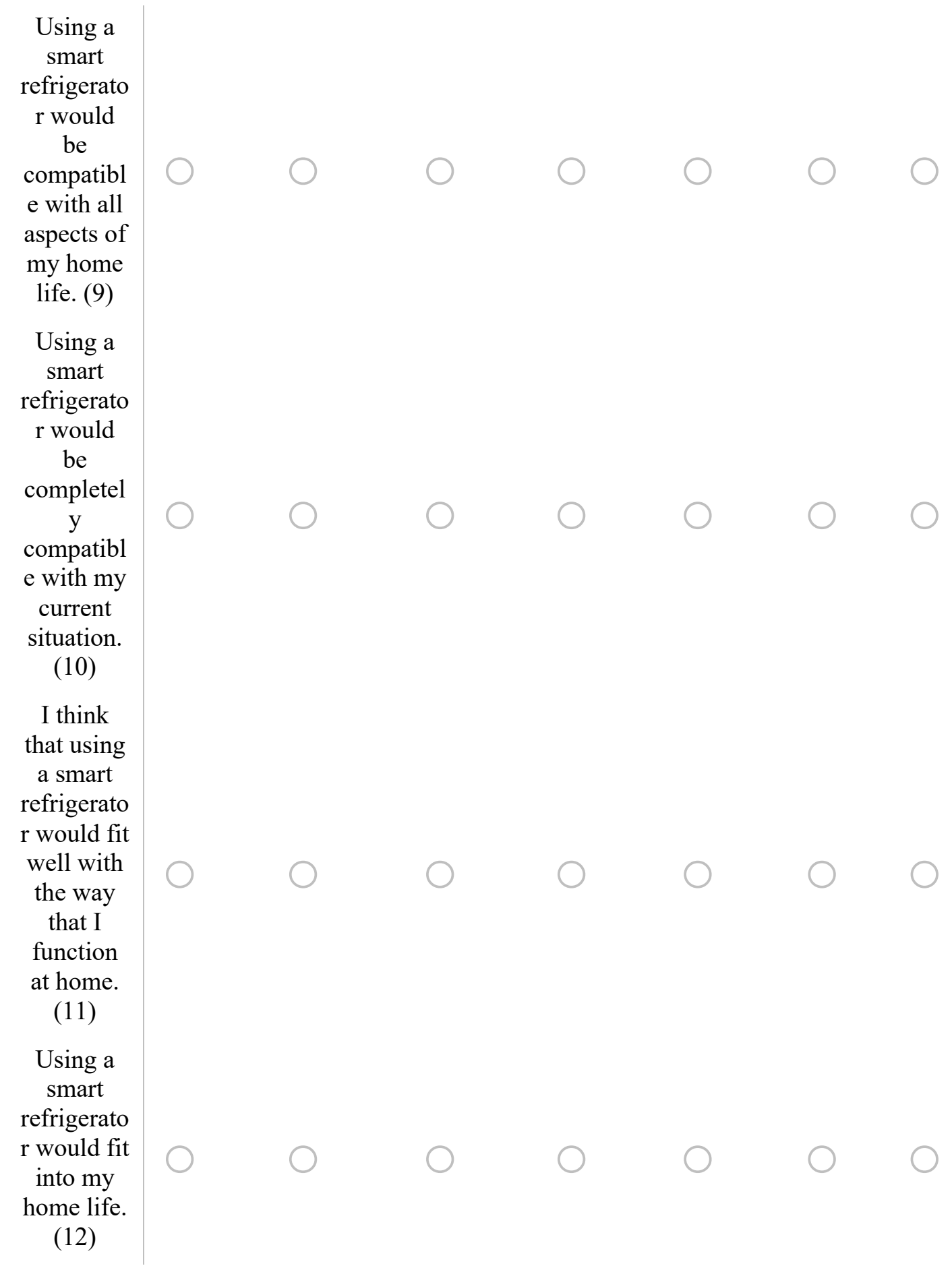




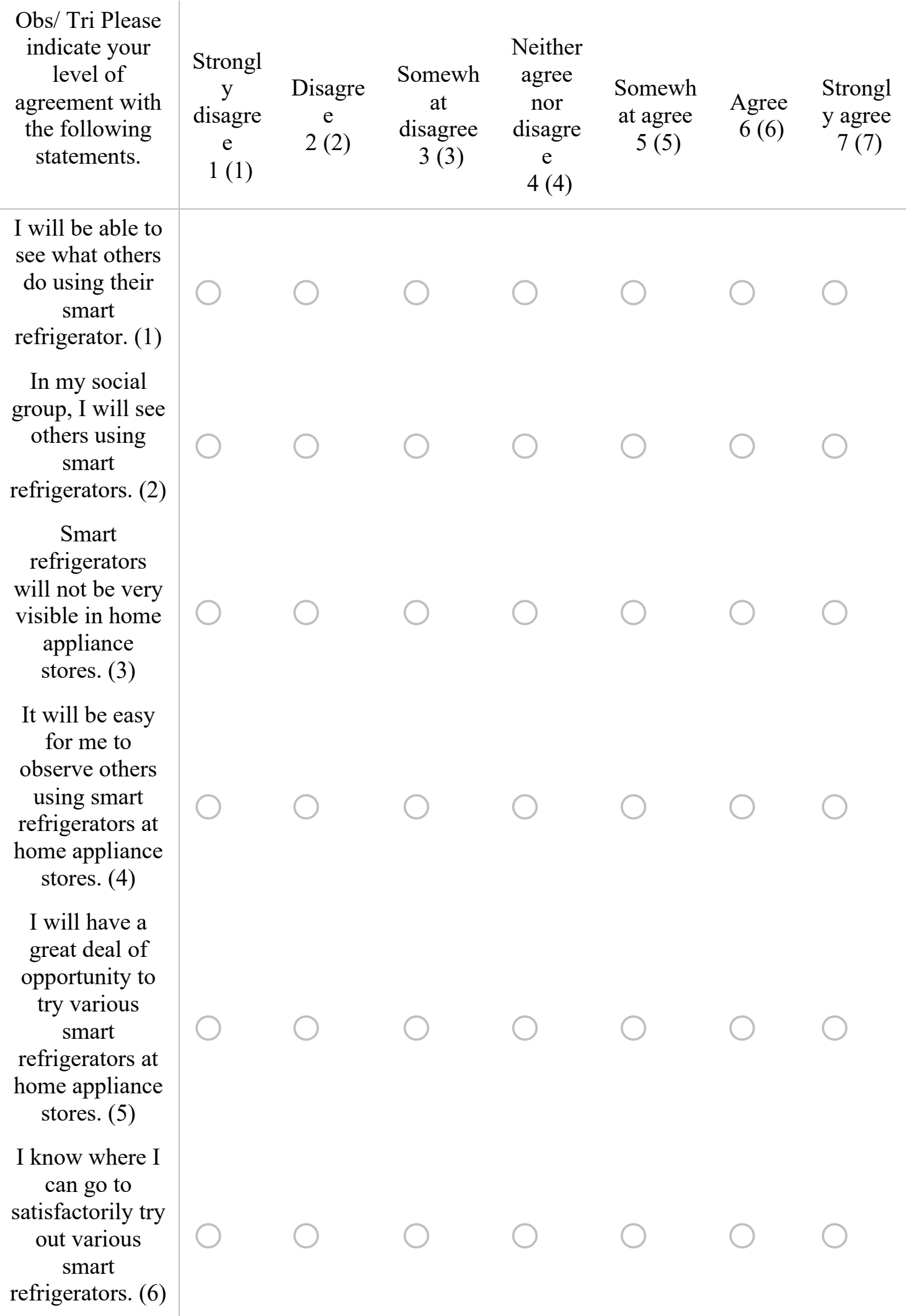




\begin{abstract}
A smart
refrigerator can

be available to

me to

adequately test

out its various

uses. (7)

Before deciding

whether to

purchase a

smart

refrigerator, I

will be able to

properly try it out. (8)

I will be able to use a smart

refrigerator on a trial basis long enough to see what it can do.
\end{abstract}

(9) 


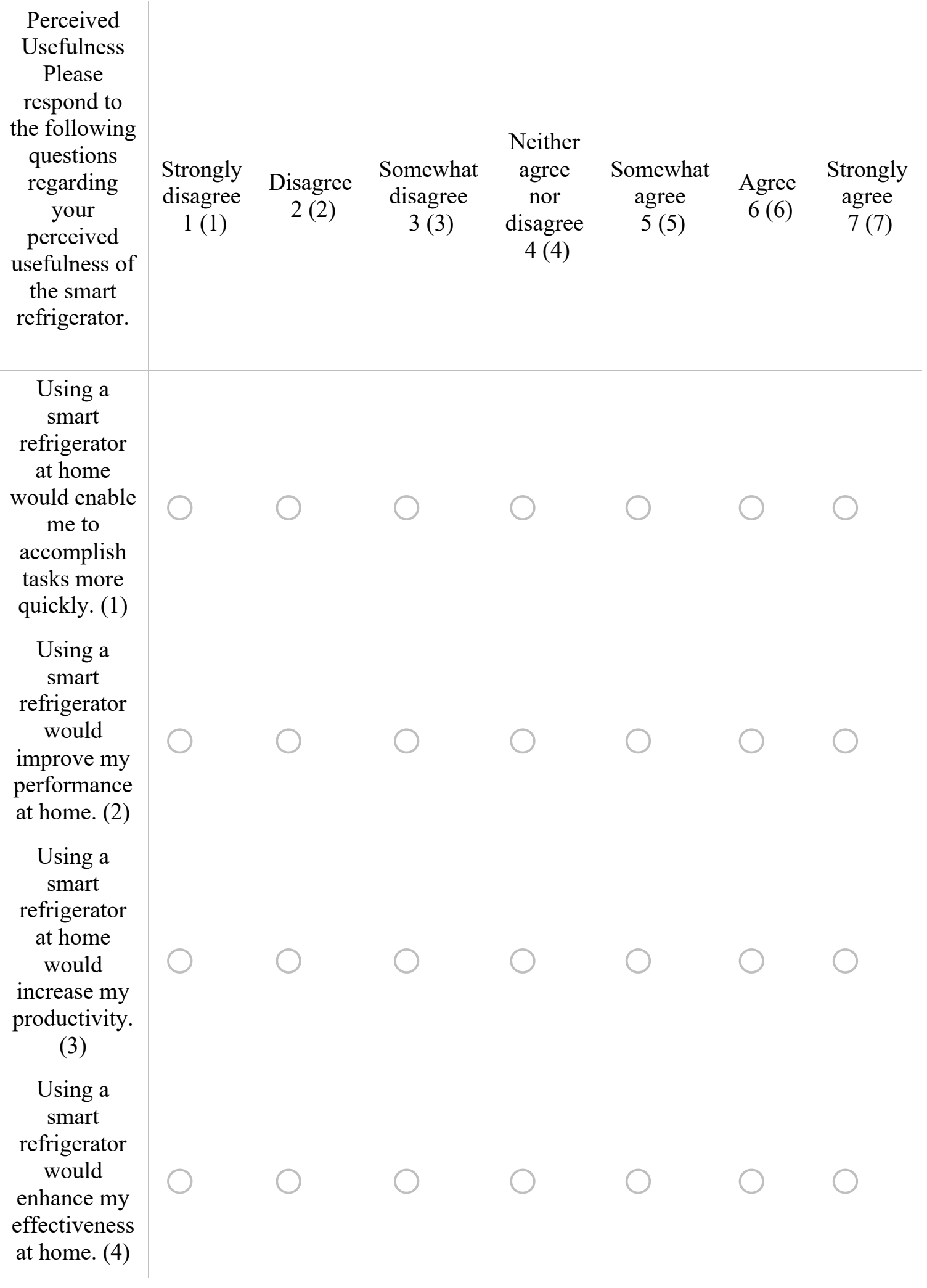




\begin{abstract}
Using a
smart

refrigerator

would make

it easier to

function at

home. (5)

I would find

a smart

refrigerator

useful in my
\end{abstract}

life. (6) 


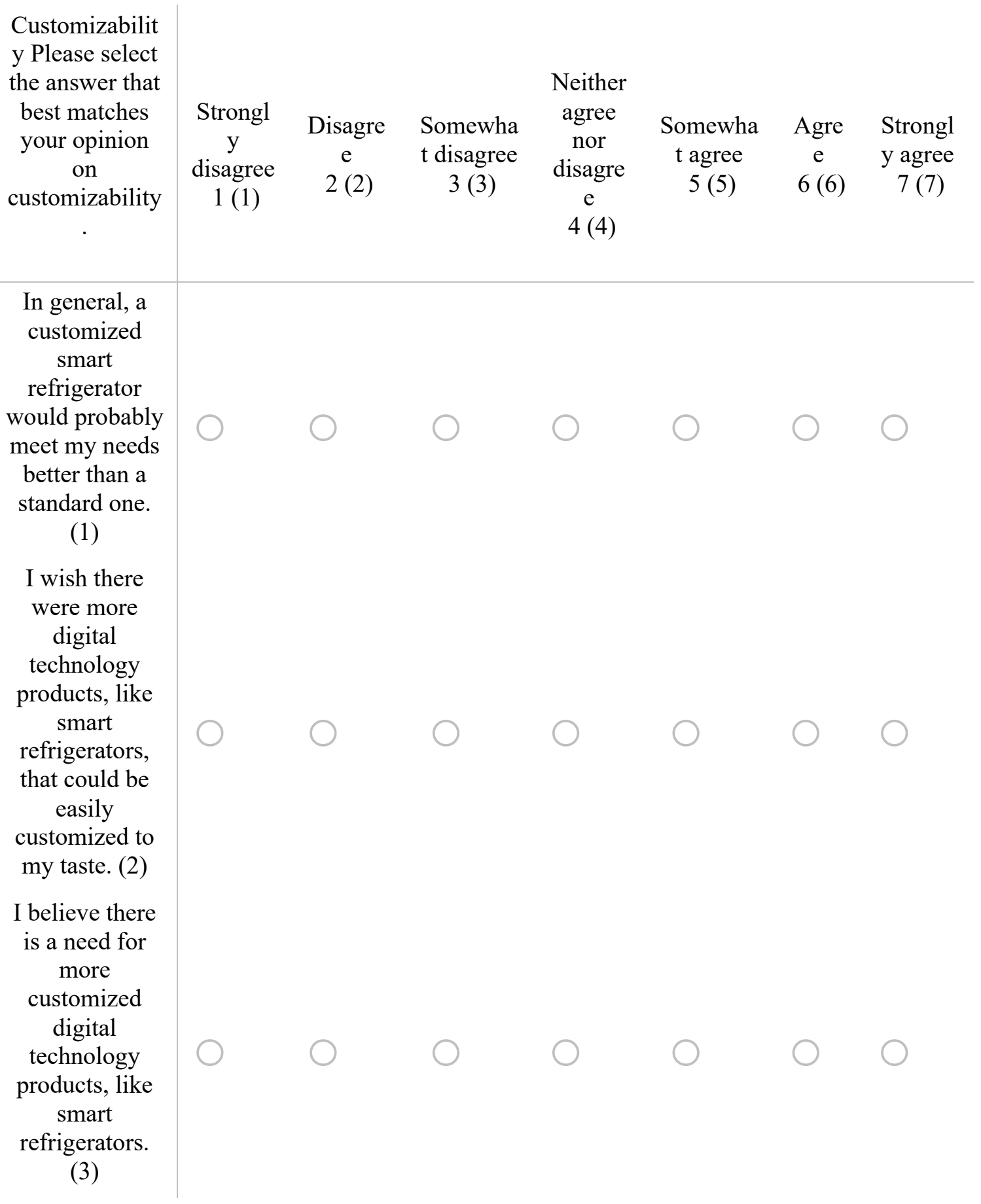




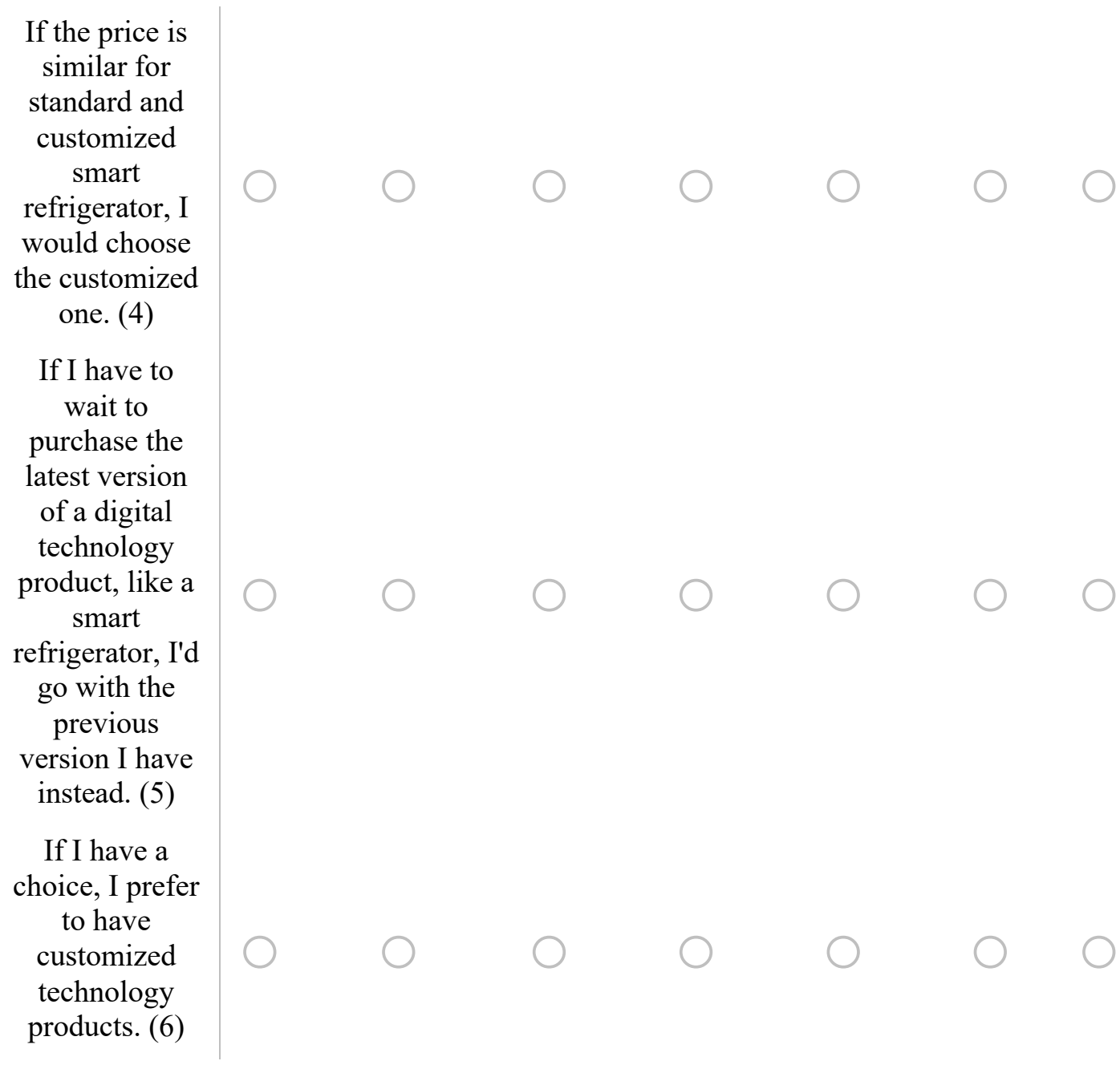


Social Influence While answering the following questions, please think of five people in your social group that you have talked with the most often in the past six months.

From how many of these people have you received (or would you receive) technologyrelated advice? (1)

How many of these people own a smart refrigerator? (2)

$0(0) \ldots 5(5)$

$0(0) \ldots 5(5)$

How many of these people have encouraged

(or would encourage) you to use a smart refrigerator? (3)

$0(0) \ldots 5(5)$

Motivation to comply Please indicate the level of importance you feel regarding the following statement.

\begin{tabular}{c|ccccc} 
& $\begin{array}{c}\text { Extremely } \\
\text { important } \\
1(1)\end{array}$ & $\begin{array}{c}\text { Very } \\
\text { important } \\
2(2)\end{array}$ & $\begin{array}{c}\text { Moderately } \\
\text { important }\end{array}$ & $\begin{array}{c}\text { Slightly } \\
\text { important } \\
4(3)\end{array}$ & $\begin{array}{c}\text { Not at all } \\
\text { important } \\
5(5)\end{array}$ \\
\hline $\begin{array}{c}\text { How much do you } \\
\text { care about the } \\
\text { opinions of these five } \\
\text { people regarding }\end{array}$ & & & & & 5 \\
their opinion about \\
new technologies?
\end{tabular}


Concern Indicate the extent to which you are concerned about the following. 


\begin{tabular}{|c|c|c|c|c|c|}
\hline & $\begin{array}{c}\text { Not at all } \\
\text { concerned } \\
1(1)\end{array}$ & $\begin{array}{c}\text { Slightly } \\
\text { concerned } \\
2(2)\end{array}$ & $\begin{array}{c}\text { Somewhat } \\
\text { concerned } \\
3(3)\end{array}$ & $\begin{array}{c}\text { Moderately } \\
\text { concerned } \\
4(4)\end{array}$ & $\begin{array}{c}\text { Extremely } \\
\text { concerned } \\
5(5)\end{array}$ \\
\hline $\begin{array}{l}\text { I am } \\
\text { concerned } \\
\text { that the } \\
\text { information I } \\
\text { give to my } \\
\text { smart } \\
\text { refrigerator } \\
\text { could be } \\
\text { misused. (1) }\end{array}$ & & 0 & & & \\
\hline $\begin{array}{c}\text { I am } \\
\text { concerned } \\
\text { that a person } \\
\text { can find } \\
\text { private } \\
\text { information } \\
\text { about me by } \\
\text { using or } \\
\text { hacking into } \\
\text { my smart } \\
\text { refrigerator. } \\
\text { (2) }\end{array}$ & D & 0 & & & D \\
\hline $\begin{array}{c}\text { I am } \\
\text { concerned } \\
\text { about } \\
\text { inputting } \\
\text { information } \\
\text { into my smart } \\
\text { refrigerator } \\
\text { because of } \\
\text { what others } \\
\text { might do with } \\
\text { it. (3) }\end{array}$ & 0 & 0 & $\bigcirc$ & 0 & 0 \\
\hline
\end{tabular}




\begin{tabular}{c|} 
I am \\
concerned \\
about \\
inputting \\
information \\
into my smart \\
refrigerator \\
because it \\
could be used \\
in a way I did \\
not foresee. \\
$(4)$
\end{tabular}

End of Block: Privacy concern

Start of Block: Have purchased/ some demographic questions

Have Purchased Have you ever purchased or owned a smart refrigerator for your personal use?

Yes (1)

No (2) 
wd purch/ win/ parnt Please indicate your level of agreement with the following statements.

\begin{tabular}{|c|c|c|c|c|c|c|c|}
\hline & $\begin{array}{c}\text { Strongly } \\
\text { disagree } \\
1(1)\end{array}$ & $\begin{array}{c}\text { Disagree } \\
2(2)\end{array}$ & $\begin{array}{c}\text { Somewhat } \\
\text { disagree } \\
3(3)\end{array}$ & $\begin{array}{c}\text { Neither } \\
\text { agree } \\
\text { nor } \\
\text { disagree } \\
4(4)\end{array}$ & $\begin{array}{c}\text { Somewhat } \\
\text { agree } \\
5(5)\end{array}$ & $\begin{array}{c}\text { Agree } \\
6(6)\end{array}$ & $\begin{array}{c}\text { Strongly } \\
\text { agree } \\
7(7)\end{array}$ \\
\hline $\begin{array}{l}\text { I would } \\
\text { consider } \\
\text { purchasing } \\
\text { a smart } \\
\text { refrigerator } \\
\text { for my } \\
\text { personal } \\
\text { use. (1) }\end{array}$ & 0 & 0 & 0 & ) & D & & ) \\
\hline $\begin{array}{l}\text { If I were to } \\
\text { win a smart } \\
\text { refrigerator, } \\
\text { I would } \\
\text { choose to } \\
\text { use it. (2) }\end{array}$ & 0 & 0 & 0 & ) & C & ) & ) \\
\hline $\begin{array}{l}\text { My parents } \\
\text { keep up } \\
\text { with } \\
\text { important } \\
\text { new } \\
\text { technologies } \\
\text { (3) }\end{array}$ & 0 & $\bigcirc$ & 0 & $\bigcirc$ & 0 & $\bigcirc$ & $\cap$ \\
\hline
\end{tabular}

Born What year were you born?

$\boldsymbol{\nabla} 2000$ (1) ... 1900 (101) 
SES Please answer the following questions to the best of your ability.

\#(2)

How many bedrooms were in the home in which you were raised? (2)

How many people (adults and children) including yourself lived in the home in which you were raised? (1)

Gender What is your preferred gender identity?

Male (1)

Female (2)

Other (3)

Race With which race do you identify?

$\nabla$ White/Caucasian (1) ... Other (7)

Comments Is there anything else you would like to share with us about the survey topic? 


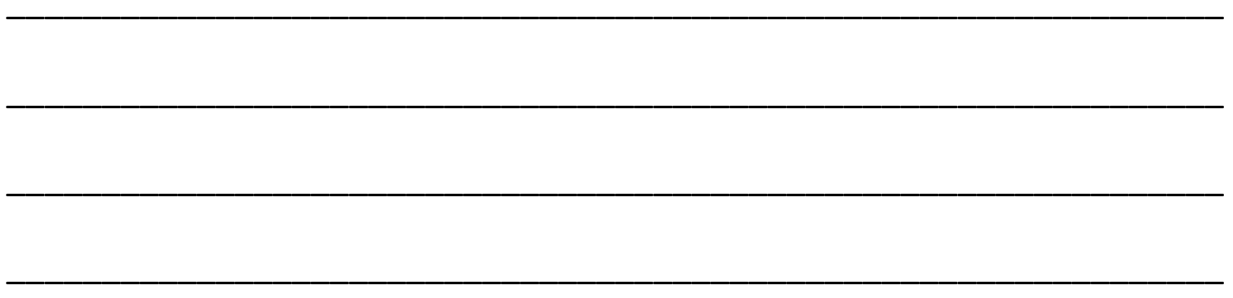

End of Block: Demographics 


\section{Appendix B: Human Subjects Approval}

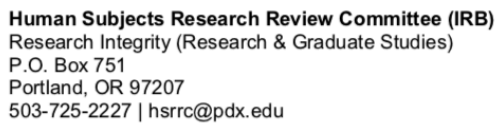

Date: December 14, 2018

To: $\quad$ Lauren Frank / Laura Glass; Communications

From: Jack Barbera, IRB Chair

Re: $\quad$ IRB Exemption Determination for your protocol \# 184904, entitled: "Digital Technology Adoption and the Diffusion of Innovations Theory."

\section{Notice of IRB Determination - Initial Review Exempt Review Category 2; as per Title 45 CFR Part 46}

In accordance with your request, the PSU Research Integrity office, on behalf of the IRB (Human Subjects Research Review Committee), has reviewed and determined your protocol is in compliance with PSU policies and DHHS regulations covering the protection of human subjects. Research Integrity has determined your protocol qualifies for exempt review and is satisfied that your provisions for protecting the rights and welfare of all subjects participating in the research are adequate. Please note the following requirements:

Approval: You may proceed to conduct this research study after receipt of this determination letter, and the research must be conducted according to the plans and protocol submitted (copy enclosed).

Consent: You must use IRB-exempted consent materials with study participants. Signed consent is waived; a written consent statement is required.

Changes to Protocol: Any changes in the proposed study, whether to procedures, survey instruments, consent forms or cover letters, must be outlined and submitted to Research Integrity immediately. The proposed changes cannot be implemented before they have been determined to not change the level of review (exempt) by Research Integrity, and an IRB memo of such determination has been received by the researcher.

Adverse Reactions and/or Unanticipated Problems: If any adverse reactions or unanticipated problems occur as a result of this study, you are required to notify Research Integrity office within 5 days of the event. If the issue is serious, approval may be withdrawn pending an investigation by the IRB.

Completion of Study: Please notify Research Integrity as soon as your research has been completed. Study records, including protocols and signed consent forms for each participant, must be kept by the investigator in a secure location for five years following completion of the study (or per any requirements specified by the project's funding agency).

If you have questions or concerns, please contact the Research Integrity office in Research \& Graduate Studies at hsrre@pdx.edu or call 503-725-2227. 